\title{
The attributes of plakins in cancer and disease: perspectives on ovarian cancer progression, chemoresistance and recurrence
}

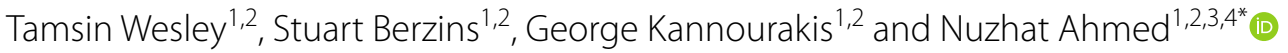

\begin{abstract}
The plakin family of cytoskeletal proteins play an important role in cancer progression yet are under-studied in cancer, especially ovarian cancer. These large cytoskeletal proteins have primary roles in the maintenance of cytoskeletal integrity but are also associated with scaffolds of intermediate filaments and hemidesmosomal adhesion complexes mediating signalling pathways that regulate cellular growth, migration, invasion and differentiation as well as stress response. Abnormalities of plakins, and the closely related spectraplakins, result in diseases of the skin, striated muscle and nervous tissue. Their prevalence in epithelial cells suggests that plakins may play a role in epithelial ovarian cancer progression and recurrence. In this review article, we explore the roles of plakins, particularly plectin, periplakin and envoplakin in disease-states and cancers with emphasis on ovarian cancer. We discuss the potential role the plakin family of proteins play in regulating cancer cell growth, survival, migration, invasion and drug resistance. We highlight potential relationships between plakins, epithelial-mesenchymal transition (EMT) and cancer stem cells (CSCs) and discuss how interaction of these processes may affect ovarian cancer progression, chemoresistance and ultimately recurrence. We propose that molecular changes in the expression of plakins leads to the transition of benign ovarian tumours to carcinomas, as well as floating cellular aggregates (commonly known as spheroids) in the ascites microenvironment, which may contribute to the sustenance and progression of the disease. In this review, attempts have been made to understand the crucial changes in plakin expression in relation to progression and recurrence of ovarian cancer.
\end{abstract}

Keywords: Plakins, Ovarian cancer, Tumour cells, Ascites, Chemoresistance, Chemotherapy

\section{Background}

The plakins are a large versatile family of proteins present in different tissues of the body that are well known for their roles in providing cytoskeletal integrity and organizational support to cellular adhesion complexes [1]. They provide strength to cells exposed to mechanical stress, such as muscle and skin, linking intermediate filaments that form the cell cytoskeleton and mediate

*Correspondence: nuzhata@unimelb.edu.au

${ }^{1}$ Fiona Elsey Cancer Research Institute, Ballarat Technology Central Park, Suites 23-26, 106-110 Lydiard Street South, Ballarat, VIC 3353, Australia

Full list of author information is available at the end of the article cadherin associated cell-cell junctions to provide tissue integrity $[1,2]$. Plakins also connect hemidesmosome junction complexes to the plasma membrane, nucleus and mitochondria of human cells and play a crucial role in maintaining cytoskeletal stability while at the same time act as adaptors for signalling proteins that regulate cell-extracellular matrix connections, cell-cell connection, cell migration and invasion, differentiation, and in some cases stress responses. The participation of plakins in intracellular signalling, cellular migration and differentiation makes this family of proteins an intriguing subject for cancer research [3]. original author(s) and the source, provide a link to the Creative Commons licence, and indicate if changes were made. The images or other third party material in this article are included in the article's Creative Commons licence, unless indicated otherwise in a credit line to the material. If material is not included in the article's Creative Commons licence and your intended use is not permitted by statutory regulation or exceeds the permitted use, you will need to obtain permission directly from the copyright holder. To view a copy of this licence, visit http://creativecommons.org/licenses/by/4.0/. The Creative Commons Public Domain Dedication waiver (http://creativeco mmons.org/publicdomain/zero/1.0/) applies to the data made available in this article, unless otherwise stated in a credit line to the data. 
Mammalian plakins are evolutionarily conserved and have a similar cellular organization in different tissues [2]. However, they have multiple binding sites and isomeric variations that provide them with additional roles across a range of tissues [2]. Their varied composition and binding patterns with hemidesmosomes and intermediate filaments affect tissue integrity in genetic and autoimmune diseases [2]. The most known plakins are plectin (PLEC) and desmoplakin (DSP). The remainder are envoplakin (EVPL), periplakin (PPL) and Epiplakin (EPPK1). Their cousins are the spectraplakins, microtubule-actin crosslinking factor (MACF1 also known as ACF7) and bullous pemphigus antigen 1 (BPAG1). Often the epithelial and neuronal isoforms, BPAG1e and BPAG1n are grouped with the plakins, while BPAG1a and $1 \mathrm{~b}$ are grouped with the spectraplakins, the division being based on their similar characteristics to spectrin family proteins [2].

Most of our current knowledge on the role of plakins in humans comes from studies of mammalian tissues such as skin and skeletal muscles [1]. However, very little is known about how the assembly of plakins that incorporates intermediate filaments and adaptor proteins changes with cellular transformation associated with neoplastic transformation. As a result, the molecular mechanisms that maintains plakin assembly with other adaptor and scaffolding proteins to provide cytoskeletal stability in cancer cells remains vague. In this review, we summarize our knowledge of plakins in skin and skeletal muscle biology, give an overview of recent findings about plakin biology in cancer, and discuss these findings in the setting of ovarian cancer progression and recurrence.

\section{Structure of common plakins}

Plakins are large multidomain versatile proteins that the shape the cytoskeleton of cells by linking to different microfilaments, intermediate filaments or microtubules [4]. They also connect different cytoskeletal networks within the cells and are also involved with linking the cytoskeletal networks to different sites on the plasma membrane, nuclear membranes or different organelles within various tissues [2]. All conventional plakins share a common structural design which comprises of a NH2terminal head region (plakin domain), a central coiled rod domain and a $\mathrm{COOH}$-terminal tail domain [5]. The plakin domain dominates the head region of these proteins, which is shared by mammalian plakin members [3]. In the case of EVPL, PPL and DSP the head domain also consists of a number of spectrin repeats and a Src homology 3 domain (SH3) [3]. The N-terminal end of plakins enables protein-protein interactions, for example, PPL, which interacts with PLEC and kazrin [6,7], while DSP at the $\mathrm{N}$ termini interacts with plakoglobin, also known as $\gamma$-catenin [8]. The plakin domain in the $\mathrm{N}$-terminal end also connects cell adhesion complexes and cytoskeletal networks essential for sustaining cellular architecture and maintaining tissue integrity and stability under stress conditions $[3,9,10]$. The central coiled region is involved with protein-protein dimerization, which provides strength to cytoskeleton and cell junctions, while the $\mathrm{C}$-terminal region consists of a few plakin repeat domains that interact with intermediate filaments $[3,11]$ The structural components of the plakins are illustrated in Fig. 1.

\section{Common plakin members: their structure and function in normal cell biology Desmoplakin (DSP)}

DSP has two isotypes. The first (DSPI) is about $330 \mathrm{kDa}$ in size and is predominantly found in cardiac muscle whereas the second (DSPII) is about $250-260 \mathrm{kDa}$, with a shorter rod domain than DSPI. The $\mathrm{N}$ terminal domain of DSP is where the interaction with the desmosomal proteins, including cadherins and armadillo proteins occurs. The C-terminus connects to intermediate filaments such as desmin, vimentin and keratins $[8,12,13]$.

DSP is the major protein involved with desmosome formation and cell-cell adhesion [10, 14]. It has been established that DSP can be degraded by the $26 \mathrm{~s}$ proteasome, thus modulating DSP expression and signalling [15]. The protein $\mathrm{p} 53$, known for its control of the cell cycle and apoptosis, and the related p63 are involved in the regulation of the structure and function of desmosomes. Both p53 and p63 regulate the expression of many desmosomal proteins, including DSP [16]. The tumour suppressor function of the p53 family also modulates DSP expression [16].

\section{Envoplakin (EVPL)}

EVPL is often studied in association with PPL. Both proteins were discovered through study of the skin-blistering disease, paraneoplastic pemphigus (PNP), which accompanies both benign and malignant neoplasia, diagnosed by the production of autoantibodies against proteins in the cells of skin and mucus membranes that breaks cell-cell communication resulting in skin erosion and blistering [3]. In addition, EVPL is found in a range of epithelial cells of various tissues and links intermediate filaments (IFs) and desmosomes to the cornified envelope of mature cells of stratified squamous epithelium [4]. In skin cells that have not yet formed a cornified envelope, EVPL and PPL are found near DSP at desmosomes, in an inter-desmosomal network at the cell membrane associated with keratin filaments $[4,5]$. EVPL has a p63 specific response element and its expression in the skin of mice was shown to be severely reduced in the absence of p63 protein [17]. EVPL is predicted to form heterodimers 


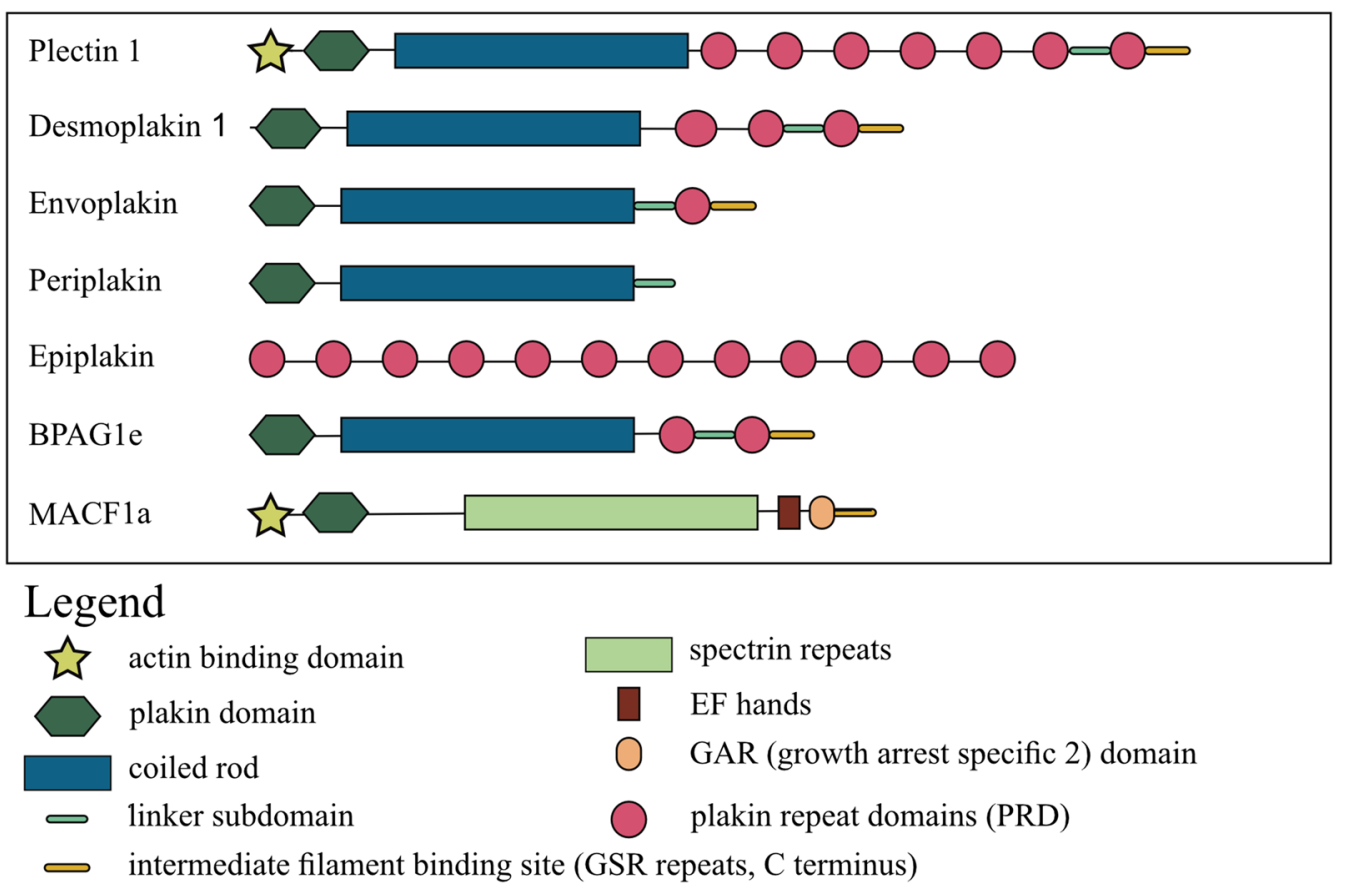

Fig. 1 Examples of plakin and spectraplakin structure, not to scale (TWesley unpublished) $[2,11,48,180]$

with PPL due to its rod domain sequence. The binding sites for intermediate filaments, including vimentin, are found in its single plakin repeat domain $[5,18]$.

\section{Periplakin (PPL)}

PPL is a $195 \mathrm{kDa}$ protein with similar structure and function as EVPL. It acts as a cytolinker between intermediate filaments and cytoskeletal proteins and forms an integral part of desmosomal plaques with cadherins and other members of the plakin family such as DSP, PLEC and EVPL [19]. In addition, PPL interacts with other non-desmosomal proteins at the plasma membrane to regulate the signalling pathways including, AKT [20], Annexin 9 [21], CD64 [22] and melanin concentrating hormone receptor 1 (MCHR1) [23]. PPL's intermediate filament binding domain is at its $\mathrm{COOH}$ terminus end, where it specifically binds vimentin and keratin 8 [5, 24]. Similar to other plakins, both PPL and EVPL associate with the plasma membrane through the $\mathrm{NH} 2$ terminus end [5]. In the cornified envelope of stratified squamous epithelial cells PPL crosslinks intermediate filaments and desmosomes and forms a heterodimer with EVPL [4, 24].

PPL is found in a wider range of human tissues, especially in tissues that are continuously exposed to mechanical dynamics such as heart, skeletal muscle and lungs. It is strongly expressed in both proximal and distal airway epithelium of lungs [25], and a recent study has shown that PPL expression is downregulated in the lung especially in the alveolar epithelial cells as a result of bleomycin-induced injury in a mouse model [26]. In the same study it was shown that deletion of PPL gene in mice improved survival from bleomycin-induced lung injury due to enhanced expression of anti-inflammatory cytokines, reduced expression of pro-fibrotic mediators and diminished response to TGF $\beta$ signalling [26], suggesting that the expression of PPL may have a role in initiating a anti-inflammatory response in lungs.

\section{Epiplakin (EPPK1)}

EPPK1 is a $550-700 \mathrm{kDa}$ protein [27] and is found as a single chain structure due to its lack of a dimerization motif. It has been identified in the oesophagus and mucous epithelial cells of the colon and stomach and is present in the epidermis and glandular cells of parotid and sweat glands [28]. In the epidermis, EPPK1 co-localises with tight junctions (zonulae occludens or occluding junctions), specifically with $\mathrm{ZO}-1$, a tight junction marker. ZO-1 is an intracytoplasmic protein that binds to junction adhesion molecules, occludin and claudin. EPPK1 is mostly concentrated in the upper layers of the epidermis, but not the granular layer whereas tight junctions are found in both the granular and upper layers. The resistance of the upper layers to shrinkage is assisted by EPPK1 [29].

EPPK1 binds to intermediate filaments, particularly keratin 8 and 18. It may be involved in intermediate 
filament phosphorylation, or binding of focal adhesion molecules, such as tyrosine-protein kinase Src, to intermediate filaments [29]. During wound healing, EPPK1 has been shown to aid keratinocyte migration [30]. Silencing of EPPK1 upsets the intermediate filament network in keratinocytes, due to its role in lateral bundling of keratins [2]. In EPPK1-null mice, the corneal epithelium showed fragility against mechanical intervention and increased migration-dependent wound healing, with decrease in cell proliferation and E-cadherin expression [30]. In the liver, after stress or injury, EPPK1 is suggested to have a chaperon role to re-organise keratin networks. Similarly, EPPK1 may potentially protect against, and respond to, stress in the pancreas [31].

\section{Plectin (PLEC)}

PLEC, a $500 \mathrm{kDa}$ protein is expressed in a large variety of cell types [2]. The protein constitutes of a number of domains organized in three major segments [11]. The $\mathrm{N}$-terminal region consists of an actin-binding domain (ABD), formed by two calponin homology domains, trailed by a plakin domain [11]. The actin binding domain binds to integrin $\alpha 6 \beta 4$, nesprin, F-actin and dystrophin $[5,32]$. The central rod domain homodimerizes to form coiled-coil interactions. However, most of the rod domain is absent in a natural rod-less splice variant which retains the PLEC protein functions [3]. The C-terminal domain consists of six plakin repeat domains which includes nine spectrin repeats (SR1-SR9) and a SH3 domain [32]. The C-terminal domain of plakin mediates binding to intermediate filaments such as vimentin [32], while the plakin domain harbours interaction with integrin $\alpha 6 \beta 4$ [33] and BPAG2 (or type XV11 collagen) [11]. In muscle cells, PLEC can bind $\beta$-dystroglycan [34] and intermediate filament $\beta$-synemin [35], and the kinase Fer [36] in fibroblasts. The binding sites of these proteins are yet to be identified.

PLEC is a major intermediate filament cytolinker, which stabilises the cell cytoskeleton through keratin rearrangement, maintains actin filament dynamics and serves as a scaffolding base for signalling molecules [37]. It also links the nuclear envelope and centrosomes, while its long rod enable cells to maintain specific localisation of interacting molecules [32]. The actin and tubulin (microtubule) networks interact and crosstalk with the intermediate filament network via the actin binding domain (ABD) of PLEC1c $[2,37]$. The phosphorylation sites of PLEC occur mainly at its C-terminus end [37]. Across the plakin family, the phosphorylation pathways are still being investigated, but so far, associations with differentiation, cell mitosis and migration have been revealed [2].
PLEC has many isoforms, arising from more than twelve first exon alternatives, giving $\mathrm{N}$-termini variations, affecting binding sites and cellular location [11, 37]. In cells of mesenchymal origin, plectin1 (PLEC1) is a significant isoform included in connective and vascular tissues, eye lens and white blood cells [37]. In muscle cells, PLEC1 is responsible for linking the nuclear and endoplasmic reticulum membrane to the intermediate filament network. This may be through nesprin-3, an outer nuclear membrane protein and its binding partner torsin A linking to PLEC1 [37]. In comparison, in connective tissues and others, isoform PLEC1b specifically targets mitochondria and potentially forms a signalling platform and manages the organelle shape through its linking to the intermediate filament network [38].

PLEC appears to be associated with several cell-signalling axes, particularly its association with the keratin organisation of cytoskeleton modulates mitogen-activated protein kinase/extracellular signal regulated kinases (MARK/Erk) pathway. PLEC deficient keratinocytes, with no links between keratins and integrin $\alpha 6 \beta 4$, have increased potential for migration [39]. Deletion of PLEC enables its disassociation with integrin $\alpha 6 \beta 4$, which trigger Erk activation with a resultant migratory behaviour $[39,40]$.

PLEC has been shown to interact with RACK1 (receptor for activated kinase $C$ ), thus modulating the protein kinase $C(\mathrm{PKC})$ signals and influencing the MAPK/Erk pathway [40]. In the absence of PLEC, RACK1 has been shown to move to the plasma membrane, from the perinucleus, where it affects PKC and also c-Src signalling, similar to that of fibroblasts and keratinocytes stimulated via external signals such as epidermal growth factor (EGF) [37] resulting in increased migration potential [39].

PLEC has also been associated with binding and modulating the proto-oncogene tyrosine-protein kinase FER and the energy-controlling AMP-activated protein kinase $[36,40]$. It also has influence on the Rho/Rac/cdc42 family of small GTPases through its binding and rearrangement of actin filaments [41]. If apoptosis is induced by CD95 or tumour necrosis factor (TNF), PLEC is an early substrate of caspase 8 [42]. PLEC through its interaction with different signalling partners affects cellular behaviour such as proliferation, migration and invasion [43-45].

In a murine model, PLEC1 (mesenchymal isotype only) deficient $\mathrm{T}$ cells isolated from lymph nodes of PLEC1 null mice have reduced chemotactic migration in vitro and reduced leucocyte infiltration during wound healing in vivo [46]. These PLEC1 null mice have a normal lifespan, compared with the total PLEC null mice (no 
isotypes) which do not survive after birth due to skin blistering [46].

\section{Spectraplakins}

The spectraplakins are a complex family with important cytolinker roles similar to both plakin and spectrin families. It is agreed that the spectraplakins distinctly include MACF1a and 1b, microtubule-actin cross linking factor 1 , also known as actin cross-linking factor 7 (ACF7), and BPAG1a and 1b, bullous pemphigoid antigen 1 (from the disease where it was first identified), also known as BP230, often called dystonin (DST). They share similar features to BPAG1e (epithelial), BPAG1n (a neuronal isoform) and PLEC. The major function of the spectraplakins is their ability to bind any of actin filaments, intermediate filaments and microtubules [3, 47, 48].

Diversity in spectraplakin structure is generated by three to four alternative first coding exons. Their N-terminal actin-binding domain, comprised of two calponin homology domains, is also present in PLEC and neuronal BPAG1n. This is subsequently followed by a protein binding plakin domain present in all plakins and spectraplakins, except EPPK1. MACF1b and BPAG1b have a centrally located intermediate filament binding in the PLEC repeat domain (sometimes referred to as plakin repeat domain, PRD). PLEC, BPAG1e and BPAG1n have this PLEC repeat domain at their $\mathrm{C}$-terminus, as does DSP and EVPL. All spectraplakins have a large quantity of alpha-helical 'spectrin repeats' which form a large rod and contribute to their bulk. They also all have a calcium binding site, two alpha helices linked by a short loop region, called an EF hand domain, due to its similarity to the third ( $\mathrm{E}$ to $\mathrm{F}$ ) calcium binding site in parvalbumin [49]. This is followed by a growth-arrest-specific 2-related (GAS2) domain and C-terminus that makes up their microtubule binding capacity $[2,3,48]$.

Despite their multiple binding sites, spectraplakins appear to crosslink just one element of the cytoskeleton most of the time, but when necessary, such as in axon growth, binding of actin and microtubules occurs simultaneously. Loss of spectraplakins creates chaos in the cytoskeletal networks, which affect many cellular functions such as adhesion, polarisation, stabilisation and positioning of the nucleus and organelles and even interrupting intracellular transport $[3,48]$.

\section{Plakins in non-cancerous disease}

The plakins are linked to several diseases, mostly involving the skin, muscle and the neurons. Many of the plakins were first described from investigation of the autoimmune conditions, paraneoplastic pemphigus (blistering, inflamed skin and mucosa with co-presenting neoplasm) and bullous pemphigoid (large, sub-epidermal blistering).
Changes in protein expression or function through genetic changes often leads to the skin condition epidermolysis bullosa simplex (EBS), a skin blistering condition with hyperkeratosis of hands and feet. MACF1 is not associated with diseases in humans, but studies in mice have found an absence of MACF1 results in embryo death during gastrulation [47]. Generally, genetic deletions of plakin proteins results in abnormal immune responses leading to diseases that results from the development of autoantibodies against plakins [2, 3]. Table 1 demonstrates a list of the currently known genetic and autoimmune pathologies resulting from loss or damage of the plakin proteins.

\section{Plakins in cancer \\ Role of DSP in cancer}

DSP is a desmosomal protein involved in cell-cell adhesion [50]. Reduced expression of DSP has been noted to increase invasion and metastasis in several cancers [51, 52]. These changes in DSP expression occurs following epithelial-mesenchymal transition (EMT), an essential biological process observed during embryogenesis and wound healing [53]. However, EMT in cancer involves downregulation of the expression of desmosomal, adherens/tight junction and cytolinker proteins such as E-cadherin, occludens, claudins, EpCAM, $\alpha 6 \beta 4$ integrin, different cytokeratins, DSP, PPL. The process also involves simultaneous upregulation of the expression of intermediate filament and extracellular matrix (ECM) associated proteins such as vimentin, fibronectin, $\mathrm{N}$-cadherin, $\beta 1, \beta 3$ and $\beta 5$ integrins and matrix metalloproteases (MMPs). These changes in desmosomal, adherens/ tight junction, cytolinker and ECM proteins is necessary for the transformed cells to undergo epithelial-mesenchymal morphological changes to facilitate motility for dissemination [54].

Reduced expression of DSP, plakoglobin and plakophilin desmosomal proteins was noted in triple negative breast and other epithelial cancers $[16,55,56]$. This occurred concurrently with enhanced expression of EMT-inducing transcription factors such as Slug, Sip1/ZEB2 (zinc finger E-box-binding homeobox 2) $[16,55,56]$. In addition, reduced expression of DSP and tight junction proteins was also noted in pancreatic tumour cell lines, which had undergone EMT [52]. Down-regulation of DSP and E-cadherin was induced in prostate cancer cell line $\mathrm{PC} 3$, in response to upregulation in microRNA (331-3p) that concurrently upregulated EMT markers, such as N-cadherin, vimentin and Snail, suggesting that DSP loss occurs with the initiation of an EMT process in transformed cells [57]. Similarly, increased expression of EMT markers, N-cadherin and fibronectin in response to greater activity of EMT 


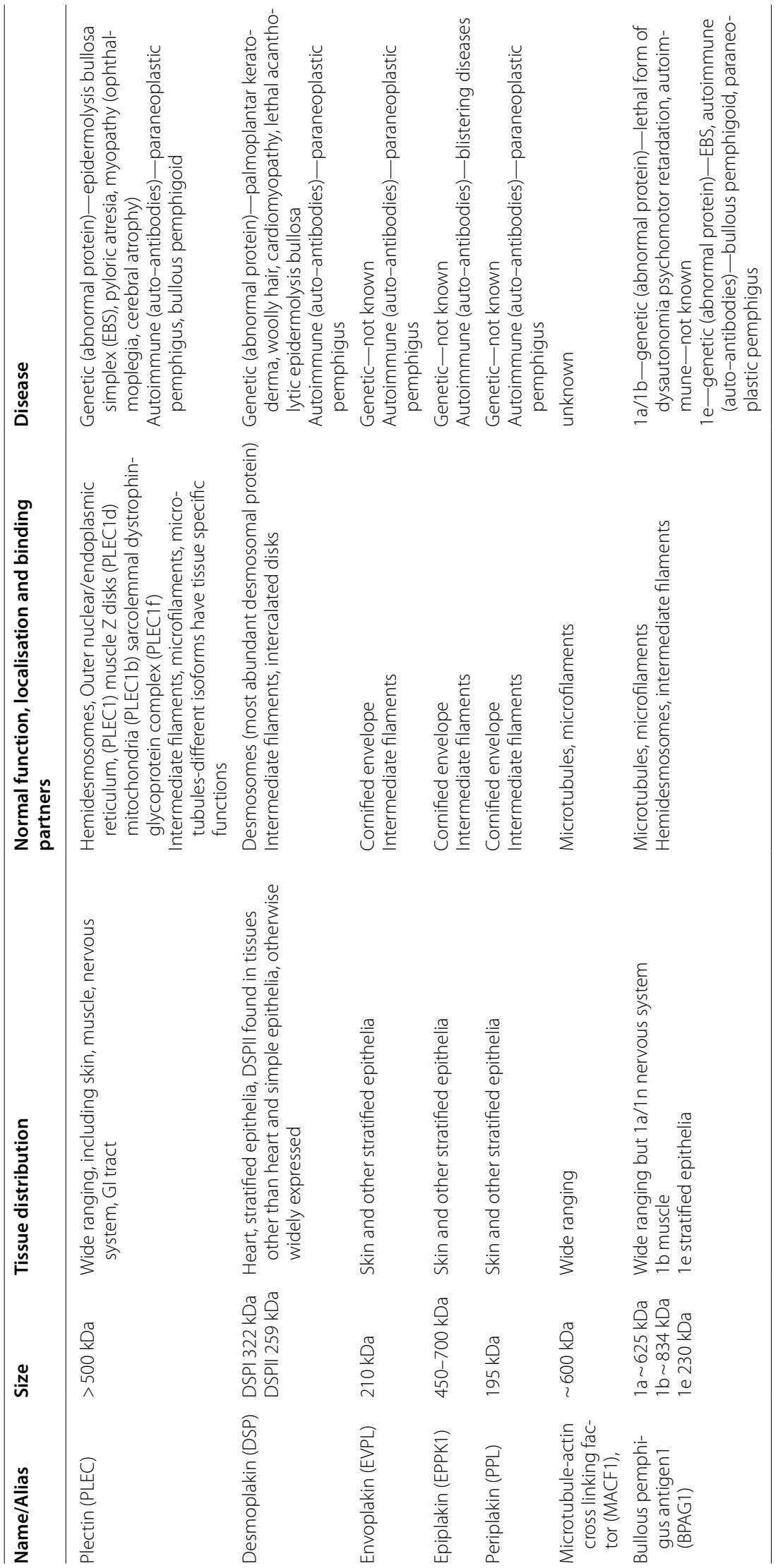


promoters Slug and Snail, concurrent with reduced levels of DSP and occludin was observed in highly migratory human pancreatic cancer cell lines compared to less aggressive cell lines [58].

Further to the above studies, alteration in the expression of DSP has been observed with the differentiation of oral pharyngeal carcinomas, where the expression of DSP in differentiated tumours that produced distant metastatic tumours within 3 years of follow up was markedly higher than in undifferentiated tumours [59]. Consistent with that, loss of DSP expression in head and neck squamous cell carcinoma (HNSCC) correlated with the loss of differentiation of primary tumour cells and presence of lymph node metastases [59, 60]. In addition, investigation of pre-cancerous dysplastic oral epithelium detected changes in DSP immunoreactivity, suggesting that desmosomal adhesion disruption is an early event in the progression of oral squamous cell carcinoma [59, 60]. Similarly, exploration of the progression of squamous intra-epithelial lesions to squamous cell carcinoma of the cervix, demonstrated increasing levels of DSP inhibition with increasing severity of disease [61, 62]. Using genetically modified mice in pancreatic neuroendocrine tumours changes in DSP and other desmosomal protein expression is an early event in the tumourigenic process and preludes changes in the expression of adheren junction proteins and tumour cell invasion [52].

DSP expression levels have shown to vary across a range of lung cancers $[51,63,64]$. In adenocarcinoma and adenosquamous carcinoma of lung minimal expression of DSP was noted [63]. Consistent with that, using an induced overexpressing DSP model of non-small cell lung cancer (NSCLC), the tumour-suppressive function of DSP behaviour was demonstrated through the inhibition of the Wnt/ $\beta$-catenin/TCF/LEF (transcription factor) pathway [51]. In that context, epigenetic silencing of DSP was observed in primary lung tumours and cell lines [51]. Contrary to that, increased DSP expression was observed in lung squamous cell carcinoma, a subset of NSCLC, which displayed increased expression and distinct distribution of other desmosomal proteins including integrin $\beta 4$. DSP expression was highest in the centre of the tumours, where the most differentiated cells were found [64].

Estrogen (E2) is suggested to have a role in modulating desmosomal protein expression and desmosome formation. Exposure of normal and malignant mammary cells to estrogen for prolonged periods resulted in an increased expression of desmosomal proteins including DSP [65]. However, a reduction in DSP expression was observed after partial inhibition of the estrogen receptor $\alpha$ [65]. Silencing of DSP expression by siRNA resulted in the prevention of E2-dependent cell adhesion, indicating there is a functional relationship between estrogen receptors, DSP and desmosome formation and thus cell adhesion. The modulation of desmosomes by estrogen and its receptor could help maintain epithelial tissue integrity and explain the lower invasiveness seen in ER $\alpha$ positive breast tumours [65].

The above studies indicate that DSP may have a tumour suppressive role in cancers and its expression may be reduced by the induction of EMT at an early stage of cancer progression. However, the tumour suppressive role of DSP in cell context dependent and relies on the differentiation status of the tumour, as enhanced expression of DSP is observed in differentiated tumours $[63,64,66]$.

\section{Role of EVPL, PPL in cancer}

EVPL, PPL and involucrin null mice showed skin fragility but also a significant resistance to developing skin tumours when challenged with tumour-stimulating TPA (12-o-tetradecanoylphorbol-13-acetate) [67]. These mice responded with increased levels of chemokines and cytokines (type 2, type 17) resulting in the recruitment of mast cells, granulocytes and CD4 $+\mathrm{T}$ cells which may lead to immune editing of tumour cells. The tumour protective mechanisms in these null mice also involved signalling between Rae-1 expressing keratinocytes and the natural killer cells having 2D receptor (NKG2D) [68]. These results suggests that absence of ENVPL, PPL and involution may activate the immune system through regulation of certain cytokines/chemokines.

In cancer, reduced expression of PPL and EVPL have been observed in oesophageal cancers [69], and the cellular localisation of PPL was noted to change with disease progression. Using immunohistochemistry, PPL expression was observed at cell-cell boundaries of normal oesophageal epithelium and dysplastic lesions, whereas it relocated to the cytoplasm in early cancers and was scarcely expressed in advanced tumours [69]. In patients with a history of smoking and who present with hypermethylation of oesophageal mucosa, DNA methylation of PPL promoter sequences leads to reduced expression of PPL and have been linked to the development of oesophageal squamous cell carcinoma [70], suggesting that loss of PPL may be one of the early events in the progression of oesophageal cancer.

Consistent with oesophageal cancer, in urothelial carcinoma of the urinary bladder, the expression of PPL was reduced with increasing pathological stages [71, 72]. Serum PPL studies of urothelial carcinoma patients indicated higher levels of PPL in muscle-invasive carcinoma, than non-muscle invasive carcinoma. However, both types of carcinoma had lower serum PPL levels than healthy controls, contributing to the pre-operative evaluation of these conditions [72]. These observations 
are consistent with the downregulation of PPL expression in colon carcinomas (which undergo EMT) compared to normal and para-carcinoma tissues [73].

PPL also plays a role in the metastasis of triple-negative breast cancer (TNBC) into the brain [74]. Reduced PPL expression has been observed in brain metastatic lesions of TNBC patients. In TNBC cell lines, reduced expression of PPL by siRNA, resulted in reduced cell migration and invasion, but had increased cell growth in soft agar, suggesting that reduced expression of PPL in brain metastasis may be important for the growth of tumours in TNBC patients [74].

In vitro experiments on cancer cell lines have shown that, the expression of PPL have varied results on cellular functions. The absence of PPL expression hinders collective migration and wound closures in epithelial cancer cells grown as monolayers as PPL facilitates the reorganization of keratin filaments at the edge of wounds [75]. Consistent with that, downregulation of PPL expression in vitro resulted in reduced cellular proliferation, adhesion and movement, linked to G0/G1 cell cycle arrest and loss of activation of PAktSer473 kinase via the PI3 kinase pathway in pharyngeal squamous cell carcinomas [76]. On the contrary, in a colon cancer cell line model (HT29), increased proliferation, migration, invasion and EMT initiating ability was noted in response to PPL knockdown [73]. However, the process was reversed in terms of decreased proliferation, migration and EMT ability when PPL was overexpressed in the same cell line, strongly suggesting an inverse relationship of PPL expression and induction of EMT in colon cancer cells [73]. Decreased proliferation in response to PPL overexpression was due to higher rate of G1/G0 cell cycle arrest resulting from increased expression of CDK inhibitors p21, p27kip and $\mathrm{p}-\mathrm{Rb}$ [73]. PPL knockdown in that model partly reversed the G0/G1 cell cycle arrest induced by PPL overexpression. These observations suggest that the effect of PPL expression on the function of cancer cells varies and is tumour context dependent, regulated by autocrine or paracrine factors that modulates cell cycle properties.

\section{Role of EPPK1 in cancer}

Both PLEC and EPPK1 are expressed in duct cells and centroacinar cells of the mature pancreas, with increasing expression of both in pre-cursor lesions and pancreatic ductal adenocarcinoma [2]. EPPK1 expression is increased in early pancreatic intraepithelial neoplasia (PanIN) but decreased levels were noted in more developed disease [77]. EPPK1 has a potential role in the EGF (epidermal growth factor) signalling pathway as its binds to the EGF receptor [78]. The participation of EPPK1 in EGF signalling was reported in pancreatic development and carcinogenesis [77, 79]. Activation of fluorescent-labelled EPPK1 in HeLa cells, originally of cervical cancer origin [29], demonstrated dynamic movement of EPPK1 protein, from one side of the cell membrane to another during migration. In HeLa cells increased migration was observed when EPPK1 expression was suppressed by knockdown while decreased migration was noted in EPPK1 overexpressed cells [29]. In 3D cell spheroids, EPPK1 was expressed in the outermost cell layer and barely detected in the interior of the spheroids, suggesting a role of EPPK1 in epithelial cell polarisation and spatial organisation [29]. However, in 2D cultures EPPK1 stabilised the keratin networks via colocalization with zonula occludens-1 (ZO-1), a marker of tight junctions, and inhibited the motility of cells by reorganizing the actin filaments [29].

\section{Role of PLEC in cancer}

Plectin expression was significantly higher in the SW480 colon cancer cell line than the lower grade HT29 colon cancer cell line [80]. In SW480 cells, in vitro suppression of PLEC by siRNA inhibited actin dynamics at scratch wound edges and reduced invasion, migration and adhesion of these cells [80]. Re-introduction of only the actinbinding domain of PLEC was sufficient to re-instigate the actin assembly at the scratch wound edge [80]. Studies have also shown that increased PLEC and vimentin expression, through PLEC complex regulation of vimentin assembly, correlate with invasive phenotypes in bladder cancer and invasion and metastasis in androgenindependent prostate cancer [43, 81]. PLEC1 expression is upregulated in oesophageal squamous cell carcinoma (SCC) and is a likely biomarker in this disease [82]. High PLEC expression has been noted in head and neck squamous cell carcinomas (HNSCC) and has been associated with increased recurrence and decreased survival rates in patients [45]. Decreased expression of PLEC by siRNA suppressed the invasion, migration and proliferation of HNSCC cells and downregulation of the Erk1/2 pathway [45]. It has been postulated that PLEC may contribute to cell migration, proliferation and invasion through its association with integrin $\beta 4$ subunit, resulting in the Erk1/2 activation $[2,45]$.

PLEC biology has been studied significantly in pancreatic cancers [83, 84]. PLEC1 has been identified as a biomarker of sufficient sensitivity and specificity for cystic fluid analysis in the early diagnosis of intra-ductal papillary mucinous neoplasms (IPMN), a group of lesions with different metastatic potential, detected by computed tomography (CT) scan [83]. PLEC1 expression enhances during the development of pancreatic intraepithelial neoplasia, PanIN stage II to PanIN stage III, precursor lesions of invasive and metastatic pancreatic ductal adenocarcinoma (PDAC) [83-85]. Later in disease progression, 
PLEC expression changes from its cell membrane localisation to a diffuse cytosolic distribution [84].

PDAC cells produce exosomes, which produce premetastatic niche environments in other tissues, such as liver [85]. These exosomes are enriched with PLEC and integrin $\beta 4$, which is necessary for PLEC inclusion [85]. Incubating PLEC-rich exosomes with cell lines devoid of cell-surface PLEC can induce abnormal cell-surface expression of PLEC [86]. Additionally, in non-PDAC cell lines, induced over expression of PLEC1a and $1 \mathrm{f}$ resulted in these isoforms being located on the cell surface [86]. Normal keratinocytes, even though expressing PLEC1a, If and integrin $\beta 4$, do not produce exosomes [86]. In PDAC, suppression of PLEC results in reduced proliferation, invasion and migration, and inhibits exosome formation. It is however, unclear whether exosome formation is stimulated by intracellular or exosomal PLEC [86].

PLEC is down regulated in hepatocellular carcinoma $[44,87]$. Further to that, in hepatocellular carcinoma (HCC) cell lines, PLEC deficiency results in irregular loosened bundles of intermediate filaments leading to observable pleomorphism [87, 88]. Induced PLEC deficiency in healthy hepatocytes also showed augmented cytoskeletons, through the altered expression and rearrangement of cytokeratin 18 (CK18). PLEC's role in the spatial organisation and anchorage of the cytoskeleton is phosphorylation-dependent, as PLEC's coordination of lamin $\mathrm{B}$ and vimentin is modulated by protein kinase A and protein kinase $C$ [35]. In addition, the breast cancer susceptibility protein, BRCA2, interacts with PLEC [89], where the BRCA2/PLEC complex is involved in nuclear duplication and centrosome formation. During the $M$ cycle, cyclin dependent kinase 1/cyclin B kinase (CDK1/ $\mathrm{CycB}$ ) actively phosphorylates PLEC, interrupting its binding of intermediate filaments and initiating network disassembly [90]. This is followed by centrosome movement resulting in perinuclear localisation potentially due to PLEC/BRCA2 complex interaction with the centrosome $[89,90]$.

\section{Ovarian cancer}

Ovarian cancer is an aggressive and progressive gynaecological neoplasm and carries a poor prognosis [91]. It is the fifth most prominent cause of cancer-related deaths amongst women worldwide [92]. At diagnosis, in majority of the cases, the cancer is manifested by an extensive intra-abdominal spread that involves peritoneum and the surrounding organs [93]. Even though extra-abdominal metastasis at diagnosis is rare, in sporadic cases that may involve metastasis to thyroid, bone, heart, breast, colon and brain [93-95]. However, mortality from ovarian cancer occurs mainly from intra-abdominal spread and death from distant metastasis is uncommon [93-95].

Despite recent advances in conventional and targeted chemotherapy, precision with debulking surgery, and the search for the elusive and reliable early diagnostic test, the five-year mortality rate of ovarian cancer patients still remains as high as $60-70 \%$ [96]. To make this challenge more complex, recent findings have classified ovarian cancer not as a single disease but as a mix of genetically different ovarian neoplasms [97]. Histologically, three main types of ovarian neoplasms have been shown to persist; cancer arising from epithelial cells or germ cells or sex cord stromal cells (hormone secreting, supporting, stromal cells within ovary) [98]. The most aggressive and common $(\sim 90 \%)$ of these neoplasms is the epithelial ovarian cancer which is further divided into four histological sub-types commonly known as mucinous, endometrioid, clear cell and serous carcinomas [97]. Among these cancers, the serous subtype constitutes nearly $80 \%$ of epithelial ovarian cancers [97].

Traditionally the ovarian surface epithelium (OSE), a single layer of epithelial cells lining the ovary, was considered as the cell of origin for serous ovarian tumours [99]. These tumours were shown to arise from OSE, which are damaged by the inflammatory cytokines and reactive oxygen species generated during the ovulation process [100]. Most of the damaged OSE is repaired during the ovulation cycle before the commencement of the next cycle [101]. However, some damaged cells persist and accumulation of these over time may lead to malignant transformation in these cells $[102,103]$. It has been postulated that under the ovulation-induced inflammatory conditions, the damaged unrepaired OSE cells may become entrapped in cyst-like structures commonly known as 'cortical inclusion cysts' (CIC) which are thought to be the origin of ovarian cancer [101]. This OSE-CIC theory relating to the origin of epithelial ovarian cancer is consistent with epidemiological data, which associates low risks of ovarian cancer in women who undergo less number of ovulatory cycles (due to pregnancy, lactation or intake of contraceptive pills) [104]. However, the theory lacks explanation for the presence of genetically diverse peritoneal carcinomas, which does not justify a CIC origin [97].

In the last fifteen years, extensive immunohistochemical analysis of the Fallopian tubes obtained during salpingo-oophorectomy from women with inherited mutation in germline breast cancer susceptibility proteins type 1,2 (BRCA 1,2) have shown that the fimbriae end of the Fallopian tube that expresses serous tubal intraepithelial carcinoma (STIC) lesions, to be a potential source of high-grade serous ovarian tumours [105, 106]. Women with BRCA1,2 mutations are predisposed 
to breast/ovarian cancer syndrome and carry a lifetime risk of $60-80 \%$ for breast cancer and $40-50 \%$ ovarian cancer respectively [107]. They develop dedifferentiated, aggressive and invasive triple negative breast cancer and high-grade serous ovarian cancer, which carry a poor prognosis [108]. The cells within STICs have a high proliferative index (indicated by high Ki67 expression) and a 'p53 signature' (mutated, non-functional p53) and exhibit the DNA damage marker $\gamma$-H2AX [109] indicating damaged DNA double strand breaks [110]. Later clinical studies have shown that $38 \%$ of this signature persists in women with BRCA1,2 mutations and $80 \%$ of that occurs in STICs located at the fimbriae end of the Fallopian tube, potentially identifying the Fallopian tube as the origin of high-grade serous ovarian cancers $[111,112]$.

\section{Initiation and progression of ovarian cancer}

The pathophysiological mechanisms of intra-abdominal spread in ovarian cancer involves a few critical steps and has been studied extensively in the last few years [113]. Metastasizing tumour cells from solid tumours may directly invade the adjacent intra-abdominal organs or may disaggregate from solid tumours and accumulate in ascites (tumour fluid) [114]. In cases of direct intra-abdominal spread these disaggregated cells floating in nutrient enriched ascites survive, either as single cells, or mostly by clustering as multicellular aggregates of cells commonly called 'spheroids' [114, 115]. Malignant ascites with free-floating single tumour cells, spheroids, immune, endothelial and stromal cells are often observed in ovarian cancer patients at diagnosis and are a common scenario in most recurring patients [96]. Increased vascular permeability and blockage of peritoneal lymphatic drainage by the disseminated cancer cells in the peritoneum is a common known cause of ascites formation [96]. Recent research indicates that the interaction between disseminated tumour cells and the peritoneal mesothelial cells play a critical role in ovarian cancer dissemination [116]. In that scenario, the shear and compressional pressure induced by ascites alters the mesothelial cell lining of the peritoneum by initiating the formation of 'tunnelling nanotubes' (TNT) on the surface of peritoneal mesothelial cells, which facilitate the transfer of mitochondria from mesothelial cells to ovarian cancer cells [117]. The growth factors and other soluble molecules in ascites also induce EMT in mesothelial cells by a process commonly known as mesothelial mesenchymal transition (MMT) which may retract the peritoneal mesothelial lining to promote the implantation of tumour cells into the peritoneal stroma [116]. However, a recent study has shown that the mesothelial cells lining the peritoneum remain intact but undergo senescence due to loss of adherent junction proteins (connexion 43, E-cadherin, occludens, desmoglein) that fosters invasion of cancer cells through the mesothelial lining to the sub-mesothelial matrix of the peritoneum to form secondary lesions $[116,118]$. This cross talk between the invading cancer cells and the peritoneal mesothelial cells is facilitated by TNTs that support the transport of mitochondria from peritoneal cells to cancer cells to promote cancer cell growth [116]. Previous studies have shown that environmental stress facilitates the formation of TNT in different types of cancer cells to reprogram metabolism in stressed cells for increased production of ATP to stimulate survival $[119,120]$. In addition, TNT-induced transfer of mitochondria from bone-marrow stromal cells to myeloid leukemic cells or endothelial cells to cancer cells during chemotherapy treatment has been shown to promote survival of resistant cancer cells [121, 122]. These observations suggests a unique role of ascites-induced compressive pressure in promoting intra-abdominal metastasis in ovarian cancer.

\section{Epithelial mesenchymal transition (EMT) and mesenchymal to epithelial transition (MET) in ovarian cancer progression} It has been postulated that EMT may initiate the early precursor lesions for high-grade serous ovarian cancer. The presence of TGF $\beta$ and inflammatory cytokines/ growth factors in the follicular fluid released during the ovulation may initiate EMT in the secretory cells of Fallopian tubes or the cells lining the CICs of OSE [102]. An association between BRCA1 and EMT has been established in breast cancer [123]. A loss of BRCA1 in mammary epithelial cells results in dedifferentiation of these cells with upregulation of CD44high/CD24low cancer stem cell (CSC) phenotype and induction of EMT [124] However, the status of BRCA mutation and EMT remains unexplored in ovarian cancer.

The EMT process has been associated with peritoneal metastasis, progression-free and overall survival in ovarian cancer, suggesting that EMT is intricately involved with ovarian cancer dissemination and therapy resistance [125]. A recent study of 174 primary ovarian and 34 metastatic tumours suggested EMT was a poor prognostic indicator for ovarian cancer by associating low E-cadherin and high Snail expression with high peritoneal dissemination, low overall and progressionfree survival in patients [126]. Ascites-derived tumour cells obtained from ovarian cancer patients were shown to undergo EMT during aggregation into spheroids, and this phenomenon was reversed when these cells were allowed to adhere on substratum in monolayer cultures [127]. E-cadherin expression was significantly reduced in aggregating spheroids compared to adherent cells in association with significant upregulation of transcription factors such as Snail, Twist and Zeb2 [127]. Studies have 
also suggested that spheroids have heterogeneous cadherin expression and enhanced E-cadherin expression is observed in established, cohesive and spherical spheroids which are difficult to disaggregate $[128,129]$. These spheroids tend to preserve their free-floating abilities in the ascites microenvironment, and metastatic dissemination only occurs if a gain in $\mathrm{N}$-cadherin expression is attained through EMT process. The process of EMT is induced by the hypoxic ascites microenvironment which activate hypoxia-induced factor 1-alpha (HIF1 $\alpha$ ) with consequent increase in the transcription of Snail resulting in EMT, increased cell motility and invasion on the sub-mesothelial layer of the peritoneum $[130,131]$. However, once the cells have migrated and colonization has occurred the process of EMT is reversed through MET for the secondary lesions to establish at a distant site [103, 132]. This continued transitional dynamics of ovarian cells between EMT and MET contributes to the metastasis and invasion of cancerous cells from primary tumours to secondary sites, and in rare cases dissemination via blood, lymph, and then invasion into other tissues $[133,134]$.

Recent studies indicate that ovarian cancer cells can exist in an intermediate 'partial or hybrid EMT (E/M)' state with characteristics of both epithelial and mesenchymal cells [132, 135]. Cells in E/M state possess a superior advantage for survival and metastasis compared to cells in either epithelial or mesenchymal state as they can readily differentiate towards either epithelial or mesenchymal state depending on the stimulus received from the tumour microenvironment [136]. Hence, E/M cells are more adaptable to migration, colonization at distant sites and are enriched in therapy-resistant CSCs, which retains the capacity for self-renewal as well as production of differentiated progenies to generate the bulk of tumours at metastatic sites or as recurrent/relapsed tumours after therapeutic treatments [137]. It is postulated that the alterations in E/M or EMT/MET phenomenon in intraperitoneal ovarian tumour cells is not due to any genetic mutation but is likely due to the origin of ovarian cancer itself which arises either from ovarian surface epithelium or differentiated columnar epithelial cells both of which contain epithelial and mesenchymal traits. It may also result from the external stimuli received by the cancer cells in the ascites microenvironment [138]. Ascites contain substantial amounts of growth factors such as lysophosphatic acid (LPA), transforming growth factor- $\beta$ (TGF $\beta$ ), epidermal growth factor (EGF), hepatocyte growth factor (HGF), interleukins (IL)1 $\beta$, IL-6, IL-8, chemokine ligand 5 (CCL-5) and chemokine receptors (CCR)-1/3/5, CCL-19/21 and CCR-7 [139], with known EMT initiating roles in ovarian cancer [114, 140].

In a recent study, immunostaining of ovarian cancer cell lines showed heterogeneous mixture of cells containing hybrid Ecad $+/$ Ncad + clones or homogenous only Ecad + or Ncad + clones [128]. However, the hybrid $\mathrm{Ecad}+/ \mathrm{Ncad}+$ clones showed greater proliferation than homogenous Ecad +or Ncad+clones, indicating once again the greater role of a $\mathrm{E} / \mathrm{M}$ phenotype in facilitating ovarian cancer growth [128]. In addition, E/M cells involved with collective migration are enriched in the outer layer of multicellular spheroids [138], coincided with a recent study which showed KRT14+leader cells enriching the outer edge of multicellular spheroids and collectively producing actin-rich invapodia to displace mesothelial cells for peritoneal invasion [141]. Loss of $\mathrm{KRT}_{14}{ }^{+}$cells diminished the invasive capacity of ovarian cancer spheroids, suggesting a potential role of $E / M$ KRT14+ cells in peritoneal invasion [142].

\section{Drug resistance, recurrence and CSCs in ovarian cancer}

Current treatment for ovarian cancer consist of surgery to remove the tumour (debulking) and any associated ascites, followed by chemotherapy. This usually results in significant reduction of tumour burden, but subsequent recurrence of tumour growth is common. Responsiveness of tumours to chemotherapy can be linked to tumour grade [143]. Low-grade tumours tend to be slower growing and less responsive to current chemotherapy, but potentially react to hormone-based treatments [143]. The high-grade tumours are more responsive to chemotherapy initially, but not hormones, with increasing lack of response to chemotherapy leading to chemo-resistant recurrent disease [143]. Current chemotherapies for ovarian cancer patients include a combination of platinum based (DNA cross-linking) and taxane based (microtubule/mitosis interference) drugs, to induce apoptosis in the bulk of cancer cells within the tumour [144]. However, a small population of resistant cells with properties of CSCs evade cancer treatments and they reinitiate cancer regrowth [145-147]. Chemotherapy has limited effectiveness against CSCs, due to the slow replication potential of these cells, high expression of efflux channels such as the ATP-binding cassette $(\mathrm{ABC})$ transporters, high response to DNA damage and repair and their ability to avoid host immune system [148, 149]. These essential plastic properties of CSCs are crucial for tumour relapse and progression and are critical for the development of CSC-specific strategies in combination with standard chemotherapies [144, 149, 150].

In ovarian cancer identification of CSCs have proved challenging as CSC markers identified in other tumours such as CD44, CD117, EpCAM, ALDH1, CD28 and OCT4 $[148,149,151,152]$ are not consistently identifiable in all ovarian tumours. These markers are not uniformly displayed [153], and this plasticity is influenced by the evolving tumour microenvironment [154]. In this 
context, it has been shown that each population of CSCs carries inherent functions within the tumour and different pools of CSCs have varied functions, which are not consistently expressed within the tumours [154]. Adding to this complexity, patients have multiple pools of CSCs within each tumour expressing different markers making specific targeting of CSCs difficult [154]. In addition, the process of EMT collaborates with CSCs, and treatment with platinum-based chemotherapy can induce EMT and CSCs in chemotherapy-treated residual cancer cells $[150,155]$. Several signalling pathways can facilitate the initiation of CSCs in ovarian cancer [154]. Among these PI3 kinase/Akt/PTEN [156, 157], Jak2/Stat3 [155], NFkB [158], Wnt [159], Notch [160] and Hedgehog [161] have been shown to facilitate tumour progression and chemotherapy resistance in ovarian cancer. Inhibiting these pathways in in vitro cultures has shown suppression of tumourigenesis and chemosensitivity in cell line and animal models $[154,155]$.

Breaks in double strand DNA occur in normal cells and in response to environmental factors such as ionising radiation [162]. Repairs to double strand breaks (DSB) are challenging for cells, with ineffective or incorrect repair leading to genomic instability $[162,163]$. The BRCA1, 2 genes are involved in DSB repair, with inherited mutations in these genes causing specific defects in the DNA repair capacity of the cell [163]. Poly (ADP ribose) polymerase 1 (PARP1) is involved in the repair of single strand DNA repair. Inhibition of PARP1 can trigger 'synthetic lethality' in cells with BRCA1/2 mutations (and other faulty DSB repair mechanisms) [163]. The use of PARP inhibitors has been successful in ovarian cancers in both BRCA1/2 mutated and non-mutated patients [163165]. This has resulted in increased progression-free survival in platinum resistant as well as sensitive patients who generally are liable to recurrence within the first few months of first line chemotherapy [163]. However, some patients undergo resistance to PARP inhibitors and ongoing genomic studies are in progress to understand that phenomenon [166]. A recent in vitro and in vivo study in ovarian cancer has demonstrated that resistance in PARP inhibitor is accrued through enrichment of CD117 and CD133 CSCs [167]. PARP inhibitor treated residual cells undergo G2-M phase cell cycle arrest, but enhance $\gamma \mathrm{H} 2 \mathrm{AX}, \mathrm{RAD} 15$ and DMC1 foci leading to accelerated DNA repair mechanism [167]. Other studies in colorectal cancer [168] have shown that combination of PARP inhibitors with radiotherapy and chemotherapy sensitises CSCs to the effect of given therapy. Recent clinical trials in ovarian cancer, which includes PARP inhibitors in combination with Bevacizumab or chemotherapy, have shown promising results in terms of overall all survival and progression-free survival [164, 169-171].

\section{Plakins in epithelial ovarian cancer}

Very little is known about the plakin biology in ovarian cancer. In terms of ovarian cancers, the influence of estrogen on DSP and desmosomes [65] correlates with metastasis and PPL expression [74]. As described above, even though the role of EMT has been studied extensively in ovarian cancer, the implication of plakin biology, intimately involved with EMT and metastasis remains unknown.

In this review, we demonstrate that plakins (PLEC, PPL and EVPL) are expressed in benign, Type I (low-grade) and Type II (high-grade) ovarian tumours. In benign and Type I tumours, the expression of plakins are confined to the epithelial lining of the tumours (indicated by positive CA125 staining) (Fig. 2). However, in Type II tumours, the epithelial boundary is lost and the expression of plakins are distributed throughout the tumours, confined to the cluster of epithelial cells (indicated by positive CA125 staining) within the tumours (Fig. 2).

Our interest in the involvement of plakins in ovarian cancer was heightened by proteomics analysis of tumour cells derived from the ascites of chemonaïve $(\mathrm{CN})$ and recurrent (CR) samples [172]. The $\mathrm{CN}$ samples were collected from ovarian cancer patients at diagnosis while the $\mathrm{CR}$ samples were collected where the disease progressed post chemotherapy treatment, between 6-20 months after first line of treatment. The tumour cells from these samples were isolated using a novel culturing technique (developed in our laboratory) without the contaminating stromal and immune cells [173]. The members of the plakin family that were differentially expressed between the $\mathrm{CN}$ and CR samples were PLEC, EVPL, PPL and EPPK1. Graphical representation of plakins and related desmosomal and hemidesmosomal associated proteins differentially expressed between $\mathrm{CN}$ and $\mathrm{CR}$ ascitesderived tumour cells [172] is provided in Fig. 3.

The study suggests that the expression of major plakins is lower in CR ascites-derived tumour cells compared to $\mathrm{CN}$ cells. The reason for the downregulation of plakins in $\mathrm{CR}$ versus $\mathrm{CN}$ samples is still unknown. However, it can be postulated that this may be due to long-term sustenance of the CR ascites-derived floating spheroids compared to $\mathrm{CN}$ spheroids. Long-term sustenance in the floating state may make proteins required for ECM attachment redundant. Our previous study has shown that longer maintenance of spheroids in in vitro cultures resulted in the downregulation of the expression of major integrins [174], consistent with the loss of $\alpha 6$ and $\beta 4$ integrin subunits in CR spheroids compared to $\mathrm{CN}$ spheroids observed in the proteomics study [172]. In addition, ascites is enriched in cytokines like TGF $\beta$ and IL-6 capable of inducing mesenchymal features in spheroids $[95,175,176]$. In this context, we have previously 


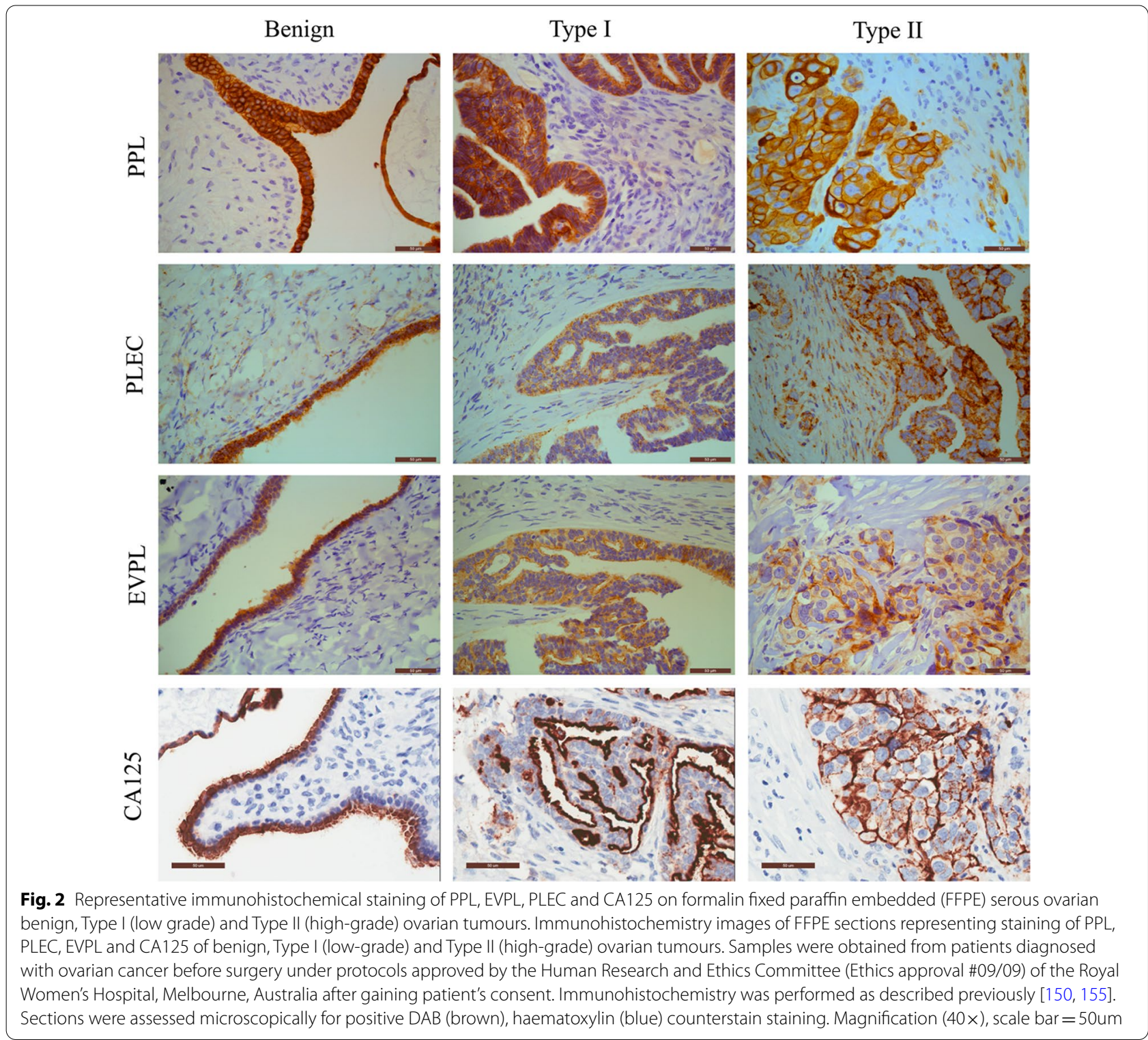

described the role of PPL in the induction of EMT in different cancers.

In this review we present a proof of concept data, Fig. 4, demonstrating that the expression of PPL, PLEC and EVPL was enhanced in a recurrent HEY ovarian cancer cell line derived mouse xenografts described previously [177]. In this experiment, three groups of immune incompetent nude mice were used. Each group was injected intraperitoneally with human HEY ovarian cancer cell line $\left(5 \times 10^{6}\right.$ cells/mouse). The first group was an untreated control, while the second (group 1) and the third group (group 2) of mice received intraperitoneal injection of paclitaxel $(15 \mathrm{mg} / \mathrm{kg}$ body weight) weekly. Treatment in groups 1 and 2 continued until the endpoint of control untreated mice at which point mice in control and group 1 (paclitaxel-treated) were euthanised. At this point, tumours in groups 1 and 2 reduced to $50 \%$ of the size of control tumours. Even though treatment in-group 2 was concluded at the same time, the mice in this group, with $50 \%$ reduced tumours compared to control, were kept alive until the experimental end-point (paclitaxelrecurrent). These mice survived 2 weeks longer than control untreated and paclitaxel-treated group 1 mice [177]. Since tumours in group 2 mice, reduced in size on paclitaxel treatment but regained regrowth when they were left untreated, the mice in this group can be treated clinically as a recurrent group. Significant elevation in PPL and PLEC staining in recurrent group 2 compared 

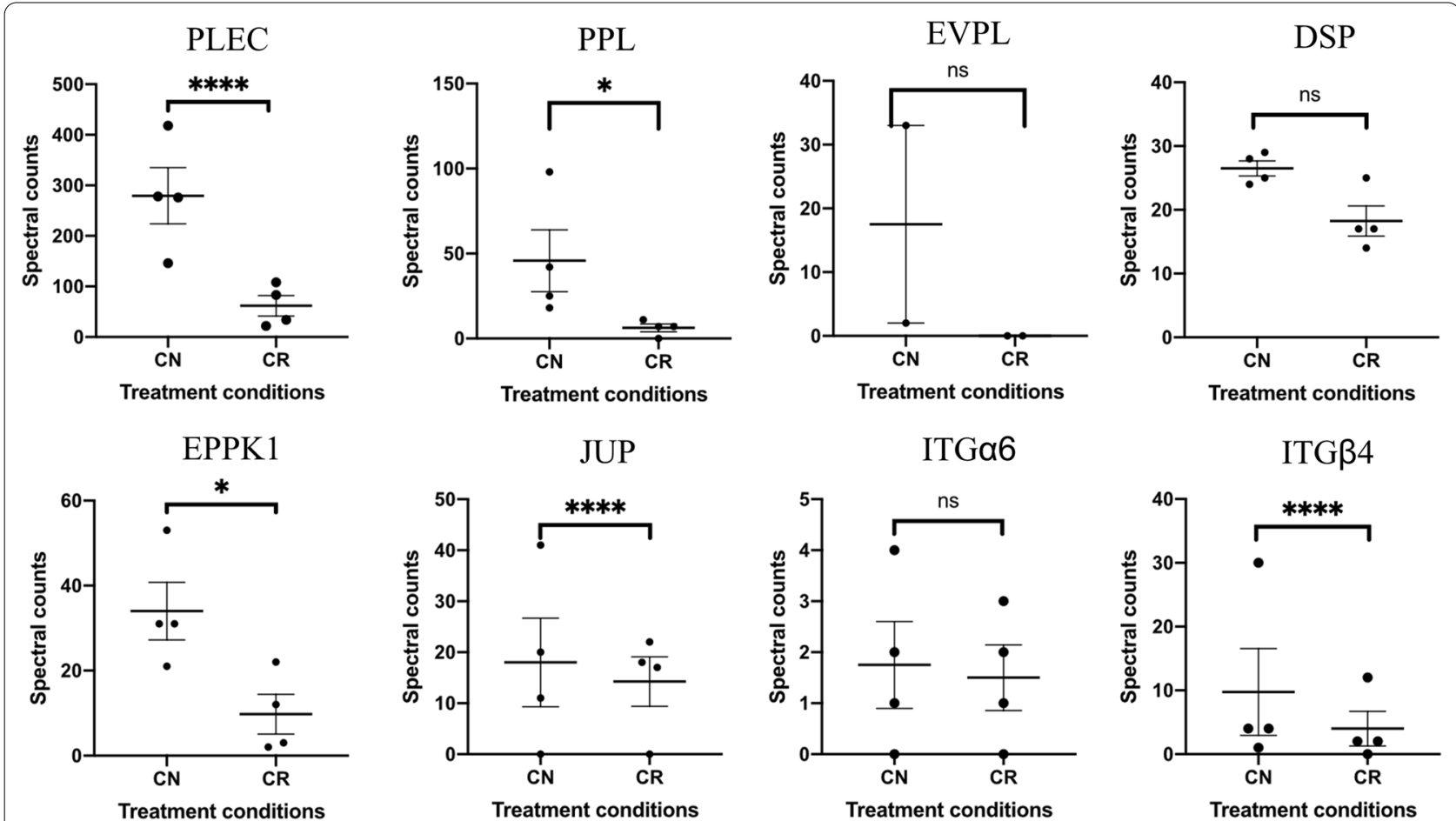

Fig. 3 Proteomic based spectral counts of PLEC, PPL, EVPL, DSP, EPPK1, junction plakoglobin (JUP) and plectin-associated a6 and $\beta 4$ integrin subunits in $C N$ and $C R$ ascites-derived ovarian cancer cells ( \pm SEM, $n=4$ for both $C N$ and $C R$ ) previously described in proteomics study [172]. Statistical significance was determined by a Chi-square test and is indicated by ${ }^{*} p<0.05$; ${ }^{* * *} p<0.0001$; ns, not significant

to group 1 (paclitaxel-treated and culled at the same time as control) and the control group (Fig. 4) was observed by immunohistochemistry, suggesting a potential link between PPL and PLEC expression, paclitaxel resistance and subsequent recurrence in ovarian cancer.

Our previous studies have also shown a sustained loss of PLEC and vimentin in an OCT4A knockdown HEY ovarian cancer cell line [152]. OCT4 is a transcription factor, with the OCT4A variant being required to maintain the self-renewal properties of stem cells and is a nuclear marker of embryonic and CSCs [178]. We have previously shown that stable knockdown of OCT4A in HEY ovarian cancer cells resulted in decreased proliferation, migration and increased chemosensitivity to cisplatin in vitro [179]. Intraperitoneal injection of OCT4A knockdown cells in nude mice significantly reduced the tumour burden with decreased tumour size and invasiveness in peritoneal organs [179]. This resulted in significant elevation in mice survival compared to mice injected with control cells [179]. In a later proteomics study, we identified and validated that stable knockdown of OCT4A in HEY ovarian cancer cell line and the associated xenografts showed a loss of PLEC and vimentin expression [152]. As PLEC is linked to the intermediate filament vimentin through cytoplasmic organelles, and links to nuclear envelope and centrosomes, this result was not unexpected [32]. In the same study, we showed enhanced expression of PLEC and vimentin in ovarian cancer cell lines after treatments with paclitaxel or cisplatin, which was consistent with increased expression of OCT4A in these cells [152]. These findings links novel aspects of plakin regulation connecting key ECM proteins and embryonic transcription factors (OCT4A) in the context of chemoresistance, which is profound in ovarian cancer patients, and the major cause of poor treatment outcomes.

\section{Conclusions}

This review summarises the current understanding about the structure and function of plakins and their roles in normal and diseased (including cancer) biology. Although plakins are important in maintaining the cell-cell, cell desmosome interactions and modulating signalling pathways $[2,11,48]$ their role in ovarian cancer remains unexplored. Our observation that plakins are expressed in the epithelial tumour cells of benign, Type I and Type II ovarian tumours but with distinctly different expression patterns suggest a specific role of plakins in ovarian cancer biology. Previously we have shown that plakins (PPL, DSP, PLEC, EVPL) expressed 


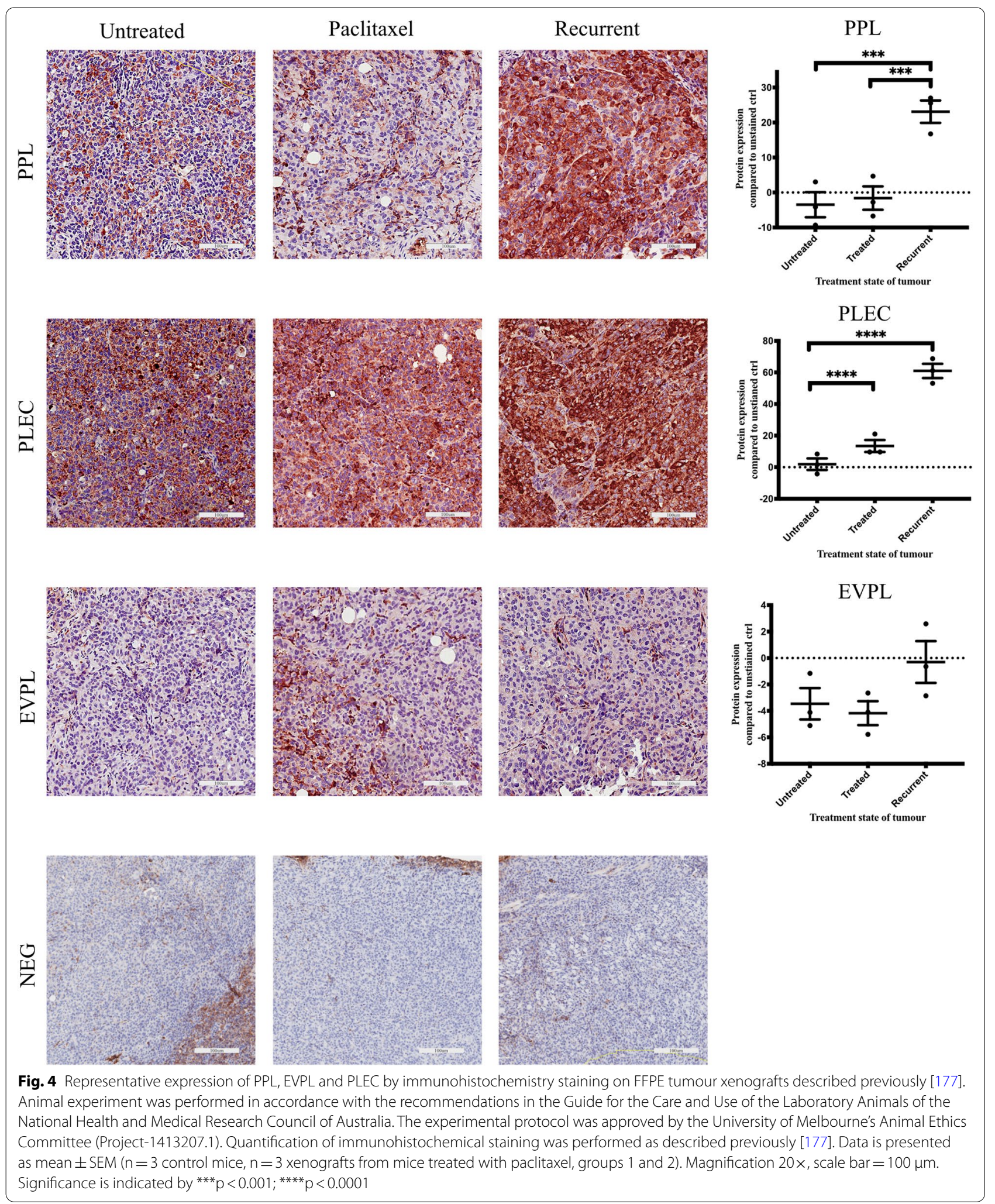




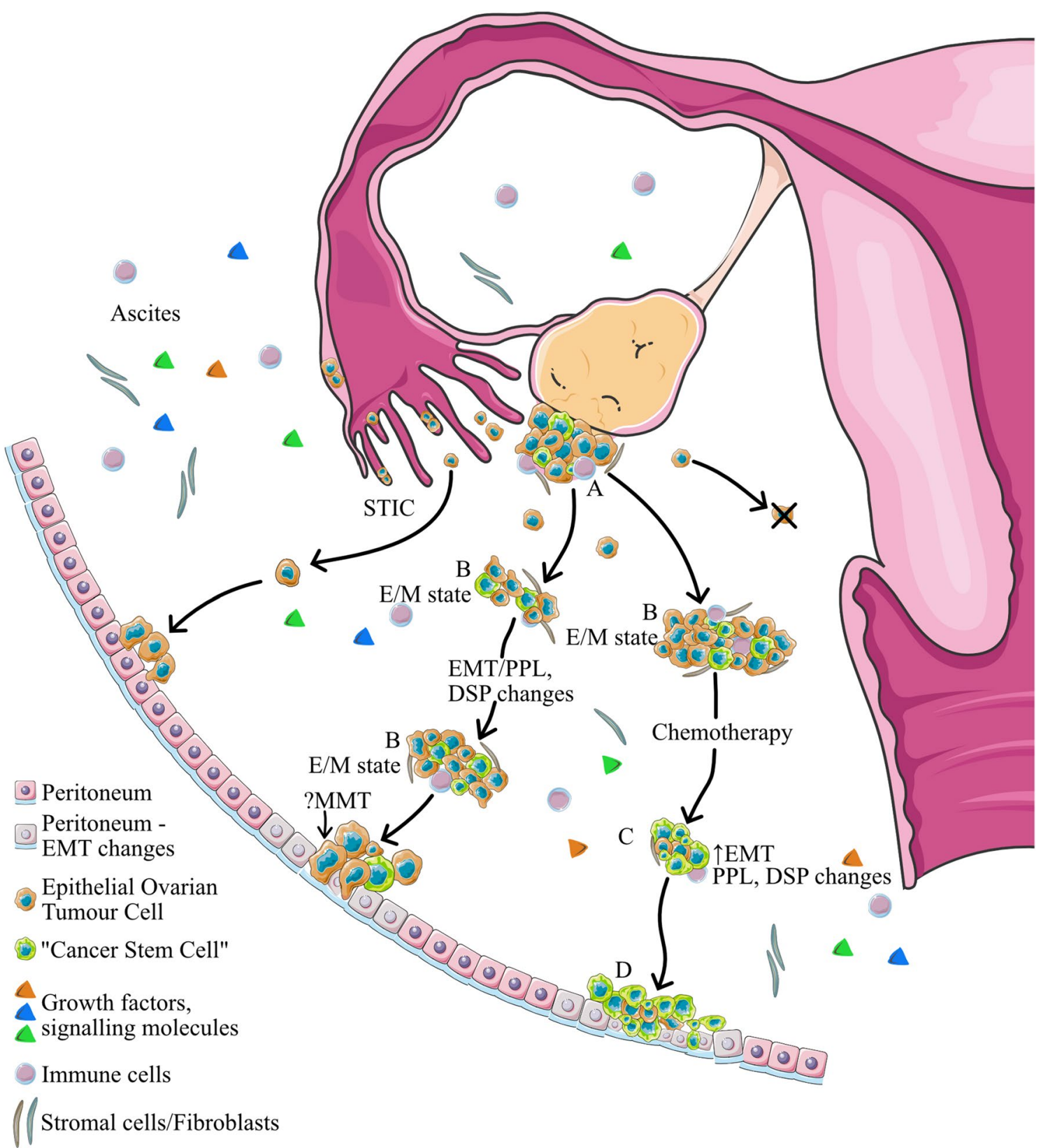

Fig. 5 Metastatic dissemination of ovarian cancer requires dynamic and reversible changes of plakin expression in the peritoneal microenvironment as the cancer progresses from primary tumour to floating multicellular spheroids and invasion onto peritoneal lining. The model includes potential involvement of DSP and PPL in STICS, the EMT process at (A) primary tumour, (B) multicellular aggregate form, (C) post-chemotherapy ascites-derived tumour cells and (D) tumour invasion of peritoneum and omentum sites where invading tumours trigger MMT and other changes in the surrounding mesothelium

in the ascites-derived tumour cells from patients with chemotherapy-treatment associated recurrence were significantly lower than plakins (PPL, DSP, EVPL, PLEC) in chemonaive ascites-derived tumour cells (Fig. 3). Our current in vivo data in a mouse model indicates significantly enhanced expression of plakins
(PPL, PLEC and EVPL) in recurrent mice xenografts that were previously reduced in size with paclitaxel treatment but underwent regrowth after stopping paclitaxel treatments, suggesting an association of plakins with chemoresistance and recurrence in ovarian cancer (Fig. 4). 
Given the known role of DSP and PPL in EMT, and the complexity of EMT-mediated metastatic process in ovarian cancer, plakin biology is expected to play an important role in each facet of ovarian cancer progression, including progression at the primary site, shedding of tumour cells in the ascites, clustering of tumour cells as spheroids and colonization at metastatic niches. Moreover, detection of PPL and PLEC levels in the serum and ascites of chemonaive and recurrent patients can be undertaken. This may facilitate better understanding of plakin biology in ovarian cancer and may aid in developing a potential role of plakins as biomarkers for early-stage detection as well as monitoring chemoresistance-associated recurrence in patients. Figure 5 describes the potential role of DSP and PPL in different progression phases of ovarian cancer.

\section{Abbreviations}

EMT: Epithelial-mesenchymal transition; CSC: Cancer stem cells; DSP: Desmoplakin; PLEC: Plectin; EVPL: Envoplakin; PPL: Periplakin; EPPK1: Epiplakin; MACF1: Microtubule-actin cross-linking factor; BPAG1: Bullous pemphigus antigen 1; ABD: Actin binding domain; RACK1: Receptor activated kinase 1; EGF: Epidermal growth factor; EBS: Epidermolysis bullosa simplex; HNSCC: Head and neck squamous cell carcinoma; NKG2D: Natural killer group 2D; CT: Computed tomography; TNBC: Triple negative breast cancer; PDAC: Pancreatic ductal adenocarcinoma; ABC: ATP-binding cassette; CK18: Cytokeratin 18; CDK1: Cyclin dependent kinase 1; CycB: Cyclin B kinase; DSB: Double strand breaks; SCC: Squamous cell carcinoma; NSCLC: Non-small cell lung cancer; PNET: Pancreatic neuroendocrine tumour; TPA: 12-0-Tetradecanoyl phorbol-13 acetate; MCHR1: Melanin concentrating hormone receptor 1; AD: Adenocarcinoma; ASC: Adenosquamous carcinoma; TNT: Tunelling nanotubule; MET: Mesenchymal-epithelial transition.

\section{Acknowledgements}

The authors wish to acknowledge the help of G Wesley in drawing Fig. 5. This work was made possible through funds from John Turner Cancer Research Funds and the Victorian State Government Operational Infrastructure Support to Hudson Institute of Medical Research.

\section{Authors' contributions}

TW undertook the analysis and literature review and participated in the writing of the article. NA conceived the idea, designed, wrote and edited the manuscript. GK and SB read and edited the final version of the manuscript. All authors have read and approved the manuscript.

\section{Funding}

This work was supported by the John Turner Cancer Research Funds to Fiona Elsey Cancer Research Institute, Ballarat, Australia. TW is the recipient of a Research Priority Area scholarship from Federation University, Australia.

\section{Availability of data and materials}

The datasets generated and/or analysed during the current study are not publicly available as it is part of a Ph.D. thesis still under progress. However, if required the data set can be obtained from the corresponding author on reasonable request.

\section{Declarations}

\section{Ethics approval and consent to participate}

The human tissue samples used in this project are from primary tumour surgical specimens donated with consent from patients under Human Ethics application approved by The Royal Women's Hospital (HEW\#09/09). Animal experiments were carried out in University of Melbourne Animal Research Facility through our Animal Ethics Approval (Project Number: 1413207.1).

\section{Consent for publication}

The human tissue samples used in this project are from primary tumour surgical specimens donated by patients after informed consent under Human Ethics application approved by The Royal Women's Hospital (HEW\#09/09), Melbourne, Australia.

\section{Competing interests}

The authors declare that they have no competing interests.

\section{Author details}

${ }^{1}$ Fiona Elsey Cancer Research Institute, Ballarat Technology Central Park, Suites 23-26, 106-110 Lydiard Street South, Ballarat, VIC 3353, Australia. ${ }^{2}$ School of Science, Psychology and Sport, Federation University Australia, Ballarat, VIC 3010, Australia. ${ }^{3}$ Department of Obstetrics and Gynaecology, University of Melbourne, Melbourne, VIC 3052, Australia. ${ }^{4}$ Centre for Reproductive Health The Hudson Institute of Medical Research and Department of Translational Medicine, Monash University, Melbourne, VIC 3168, Australia.

Received: 9 November 2020 Accepted: 20 February 2021

Published online: 17 May 2021

References

1. Fuchs E, Karakesisoglou I. Bridging cytoskeletal intersections. Genes Dev. 2001:15(1):1-14

2. Bouameur JE, Favre B, Borradori L. Plakins, a versatile family of cytolinkers: roles in skin integrity and in human diseases. J Invest Dermatol. 2014;134(4):885-94

3. Sonnenberg A, Liem RK. Plakins in development and disease. Exp Cell Res. 2007;313(10):2189-203.

4. Ruhrberg C, Watt FM. The plakin family: versatile organizers of cytoskeletal architecture. Curr Opin Genet Dev. 1997;7:392-7.

5. DiColandrea T, Karashima T, Maatta A, Watt FM. Subcellular distribution of envoplakin and periplakin: insights into their role as precursors of the epidermal cornified envelope. J Cell Biol. 2000;151(3):573-86.

6. Boczonadi V, McInroy L, Maatta A. Cytolinker cross-talk: periplakin $\mathrm{N}$-terminus interacts with plectin to regulate keratin organisation and epithelial migration. Exp Cell Res. 2007;313(16):3579-91.

7. Groot KR, Sevilla LM, Nishi K, DiColandrea T, Watt FM. Kazrin, a novel periplakin-interacting protein associated with desmosomes and the keratinocyte plasma membrane. J Cell Biol. 2004;166(5):653-9.

8. Kang H, Weiss TM, Bang I, Weis WI, Choi HJ. Structure of the intermediate filament-binding region of desmoplakin. PLoS ONE. 2016;11(1):e0147641.

9. Kowalczyk AP, Bornslaeger EA, Borgwardt JE, Palka HL, Dhaliwal AS, Corcoran CM, Denning MF, Green KJ. The amino-terminal domain of desmoplakin binds to plakoglobin and clusters desmosomal cadherinplakoglobin complexes. J Cell Biol. 1997;3(3):773-84.

10. Delva E, Tucker DK, Kowalczyk AP. The desmosome. Cold Spring Harb Perspect Biol. 2009;1(2):25-43

11. Jefferson JJ, Leung CL, Liem RK. Plakins: goliaths that link cell junctions and the cytoskeleton. Nat Rev Mol Cell Biol. 2004;5(7):542-53.

12. Wiche G. Role of plectin in cytoskeleton organization and dynamics. J Cell Sci. 1996;111:2477-86.

13. Broussard J, Getsios S, Green K. Desmosome regulation and signaling in disease. Cell Tissue Res. 2015;360(3):501-12.

14. Nekrasova O, Green KJ. Desmosome assembly and dynamics. Trends Cell Biol. 2013;23(11):537-46.

15. Lorch JH, Thomas TO, Schmoll HJ. Bortezomib inhibits cell-cell adhesion and cell migration and enhances epidermal growth factor receptor inhibitor-induced cell death in squamous cell cancer. Cancer Res. 2007;67(2):727-34.

16. Huber O, Petersen I. 150th Anniversary series: desmosomes and the hallmarks of cancer. Cell Commun Adhes. 2015:22(1):15-28.

17. Osada M, Park HL, Nagakawa Y, Yamashita K, Fomenkov A, Kim MS, Wu G, Nomoto S, Trink B, Sidransky D. Differential recognition of response 
elements determines target gene specificity for p53 and p63. Mol Cell Biol. 2005;25(14):6077-89.

18. Fogl C, Mohammed F, Al-Jassar C, Jeeves M, Knowles TJ, RodriguezZamora P, White SA, Odintsova E, Overduin M, Chidgey M. Mechanism of intermediate filament recognition by plakin repeat domains revealed by envoplakin targeting of vimentin. Nat Commun. 2016;7:10827.

19. Garrod D, Chidgey M. Desmosome structure, composition and function. Biochim Biophys Acta (BBA) Biomembr. 2008;1778(3):572-87.

20. van den Heuvel AP, de Vries-Smits AM, van Weeren PC, Dijkers PF, de Bruyn KM, Riedl JA, Burgering BM. Binding of protein kinase $B$ to the plakin family member periplakin. J Cell Sci. 2002;115(Pt 20):3957-66.

21. Boczonadi V, Maatta A. Annexin A9 is a periplakin interacting partner in membrane-targeted cytoskeletal linker protein complexes. FEBS Lett. 2012;586(19):3090-6.

22. Beekman JM, Bakema JE, van de Winkel JG, Leusen JH. Direct interaction between FcgammaRI (CD64) and periplakin controls recepto endocytosis and ligand binding capacity. Proc Natl Acad Sci USA. 2004;101(28):10392-7.

23. Murdoch H, Feng G, Bachner D, Ormiston L, White J, Richter D, Milligan G. Periplakin interferes with $G$ protein activation by the melanin-concentrating hormone receptor-1 by binding to the proximal segment of the receptor C-terminal tail. J Biol Chem. 2005;280(9):8208-20.

24. Kazerounian S, Uitto J, Aho S. Unique role for the periplakin tail in intermediate filament association: specific binding to keratin 8 and vimentin. Exp Dermatol. 2002;11:428-38.

25. Taille C, Grootenboer-Mignot S, Boursier C, Michel L, Debray MP, Fagart J, Barrientos L, Mailleux A, Cigna N, Tubach F, et al. Identification of periplakin as a new target for autoreactivity in idiopathic pulmonary fibrosis. Am J Respir Crit Care Med. 2011;183(6):759-66.

26. Besnard V, Dagher R, Madjer T, Joannes A, Jaillet M, Kolb M, Bonniaud P, Murray LA, Sleeman MA, Crestani B. Identification of periplakin as a major regulator of lung injury and repair in mice. JCl Insight. 2018;3(5):e90163.

27. Szabo S, Wogenstein KL, Fuchs P. Functional and genetic analysis of epiplakin in epithelial cells. Methods Enzymol. 2016;569:261-85.

28. Fujiwara S, Takeo N, Otani Y, Parry DA, Kunimatsu M, Lu R, Sasaki M, Matsuo N, Khaleduzzaman M, Yoshioka H. Epiplakin, a novel member of the Plakin family originally identified as a 450-kDa human epidermal autoantigen. Structure and tissue localization. J Biol Chem. 2001;276(16):13340-7.

29. Shimada H, Nambu-Niibori A, Wilson-Morifuji M, Mizuguchi S, Araki N, Sumiyoshi H, Sato M, Mezaki Y, Senoo H, Ishikawa K, et al. Epiplakin modifies the motility of the HeLa cells and accumulates at the outer surfaces of 3-D cell clusters. J Dermatol. 2013:40(4):249-58.

30. Kokado M, Okada Y, Goto M, Ishikawa K, Miyamoto T, Yamanaka O, Fujiwara S, Saika S. Increased fragility, impaired differentiation, and acceleration of migration of corneal epithelium of epiplakin-null mice. Invest Ophthalmol Vis Sci. 2013;54(5):3780-9.

31. Szabo $S$, Wögenstein $\mathrm{KL}$, Österreicher $\mathrm{CH}$, Guldiken $\mathrm{N}$, Chen $\mathrm{Y}$, Doler C, Wiche G, Boor P, Haybaeck J, Strnad P, et al. Epiplakin attenuates experimental mouse liver injury by chaperoning keratin reorganization. J Hepatol. 2015;62(6):1357-66.

32. Wiche G, Osmanagic-Myers S, Castanon MJ. Networking and anchoring through plectin: a key to IF functionality and mechanotransduction. Curr Opin Cell Biol. 2015;32:21-9.

33. Geerts D, Fontao L, Nievers MG, Schaapveld RQJ, Purkis PE, Wheeler GN, Lane EB, Leigh IM, Sonnenberg A. Binding of integrin a6ß34 to plectin prevents plectin association with $\mathrm{F}$-actin but does not interfere with intermediate filament binding. J Cell Biol. 1999;147(2):417-34.

34. Rezniczek GA, Winter $L$, Walko G, Wiche G. Functional and genetic analysis of plectin in skin and muscle. Methods Enzymol. 2016;569:235-59.

35. Liu YH, Cheng CC, Lai YS, Chao WT, Pei RJ, Hsu YH, Ho CC. Synemin down-regulation in human hepatocellular carcinoma does not destabilize cytoskeletons in vivo. Biochem Biophys Res Commun. 2011;404(1):488-93.

36. Lunter PC, Wiche G. Direct binding of plectin to Fer kinase and negative regulation of its catalytic activity. Biochem Biophys Res Commun. 2002;296(4):904-10.

37. Wiche G, Winter L. Plectin isoforms as organizers of intermediate filament cytoarchitecture. BioArchitecture. 2011;1(1):14-20.
38. Winter L, Abrahamsberg C, Wiche G. Plectin isoform $1 \mathrm{~b}$ mediates mitochondrion-intermediate filament network linkage and controls organelle shape. J Cell Biol. 2008;181(6):903-11.

39. Osmanagic-Myers S, Gregor M, Walko G, Burgstaller G, Reipert S, Wiche G. Plectin-controlled keratin cytoarchitecture affects MAP kinases involved in cellular stress response and migration. J Cell Biol. 2006:174(4):557-68.

40. Osmanagic-Myers S, Wiche G. Plectin-RACK1 (receptor for activated C kinase 1) scaffolding: a novel mechanism to regulate protein kinase $C$ activity. J Biol Chem. 2004;279(18):18701.

41. Andrä K, Nikolic B, Stöcher M, Drenckhahn D, Wiche G. Not just scaffolding: plectin regulates actin dynamics in cultured cells. Genes Dev. 1998;12(21):3442.

42. Stegh AH, Herrmann $H$, Lampel S, Weisenberger D. Identification of the cytolinker Plectin as a major early in vivo substrate for caspase 8 during CD95- and tumour necrosis factor receptor-mediated apoptosis. Mol Cell Biol. 2000;20(15):5665-79.

43. Burch TC, Watson MT, Nyalwidhe JO. Variable metastatic potentials correlate with differential plectin and vimentin expression in syngeneic androgen independent prostate cancer cells. PLOS ONE. 2013;8(5):e65005

44. Cheng C, Lai Y-CC, Lai Y-S, Hsu Y-H, Chao W-T, Sia K-C, Tseng Y-H, Liu Y-H. Transient knockdown-mediated deficiency in plectin alters hepatocellular motility in association with activated FAK and Rac1-GTPase. Cancer Cell Int 2015:15:29.

45. Katada K, Tomonaga T, Satoh M, Matsushita K, Tonoike Y, Kodera Y, Hanazawa T, Nomura F, Okamoto Y. Plectin promotes migration and invasion of cancer cells and is a novel prognostic marker for head and neck squamous cell carcinoma. J Proteomics. 2012;75(6):1803-15.

46. Abrahamsberg C, Fuchs P, Osmanagic-Myers S, Fischer I, Propst F, ElbeBürger A, Wiche $\mathrm{G}$. Targeted ablation of plectin isoform 1 uncovers role of cytolinker proteins in leukocyte recruitment. Proc Natl Acad Sci USA. 2005;102(51):18449

47. Huelsmann S, Brown NH. Spectraplakins. Curr Biol CB. 2014;24(8):R307-308.

48. Zhang J, Yue J, Wu X. Spectraplakin family proteins—cytoskeletal crosslinkers with versatile roles. J Cell Sci. 2017;130(15):2447-57.

49. Cates MS, Berry MB, Ho EL, Li Q, Potter JD, Phillips GN Jr. Metal-ion affinity and specificity in EF-hand proteins: coordination geometry and domain plasticity in parvalbumin. Structure. 1999;7(10):1269-78.

50. Brooke MA, Nitoiu D, Kelsell DP. Cell-cell connectivity: desmosomes and disease. J Pathol. 2012;226(2):158-71.

51. Yang L, Chen Y, Cui T, Knosel T, Zhang Q, Albring KF, Huber O, Petersen I. Desmoplakin acts as a tumor suppressor by inhibition of the Wnt/ beta-catenin signaling pathway in human lung cancer. Carcinogenesis. 2012;33(10):1863-70

52. Chun MG, Hanahan D. Genetic deletion of the desmosomal component desmoplakin promotes tumor microinvasion in a mouse model of pancreatic neuroendocrine carcinogenesis. PLoS Genet. 2010;6(9):e1001120.

53. Yang J, Weinberg RA. Epithelial-mesenchymal transition: at the crossroads of development and tumor metastasis. Dev Cell. 2008:14(6):818-29.

54. Hugo H, Ackland ML, BlickT, Lawrence MG, Clements JA, Williams ED, Thompson EW. Epithelial-mesenchymal and mesenchymal-epithelial transitions in carcinoma progression. J Cell Physiol. 2007;213(2):374-83.

55. Bailey CK, Mittal MK, Misra S, Chaudhuri G. High motility of triple-negative breast cancer cells is due to repression of plakoglobin gene by metastasis modulator protein SLUG. J Biol Chem. 2012:287(23):19472-86.

56. Vandewalle C, Comijn J, De Craene B, Vermassen P, Bruyneel E, Andersen H, Tulchinsky E, Van Roy F, Berx G. SIP1/ZEB2 induces EMT by repressing genes of different epithelial cell-cell junctions. Nucleic Acids Res. 2005;33(20):6566-78.

57. Fujii T, Shimada K, Tatsumi Y, Tanaka N, Fujimoto K, Konishi N. Syndecan-1 up-regulates microRNA-331-3p and mediates epithelial-to-mesenchymal transition in prostate cancer. Mol Carcinog. 2015;27:vi651.

58. Ding Q, Yoshimitsu M, Kuwahata T, Maeda K, Hayashi T, Obara T, Miyazaki Y, Matsubara S, Natsugoe S, Takao S. Establishment of a highly migratory subclone reveals that CD133 contributes to migration and 
invasion through epithelial-mesenchymal transition in pancreatic cancer. Hum Cell. 2012;25(1):1-8.

59. Papagerakis S, Shabana AH, Pollock BH, Papagerakis P, Depondt J, Berdal A. Altered desmoplakin expression at transcriptional and protein levels provides prognostic information in human oropharyngeal cancer. Hum Pathol. 2009;40(9):1320-9.

60. Hiraki A, Shinohara M, Ikebe T, Nakamura S, Kurahara S, Garrod DR. Immunohistochemical staining of desmosomal components in oral squamous cell carcinomas and its association with tumour behaviour. Br J Cancer. 1996;73(12):1491-7.

61. de Boer CJ, van Dorst E, van Krieken H, Jansen-van Rhijn CM, Warnaar SO, Fleuren GJ, Litvinov SV. Changing roles of cadherins and catenins during progression of squamous intraepithelial lesions in the uterine cervix. Am J Pathol. 1999;155(2):505-15.

62. Schmitt-Graeff A, Koeninger A, Olschewski M, Haxelmans S, Nitschke R, Bochaton-Piallat ML, Lifschitz-Mercer B, Gabbiani G, Langbein L, Czernobilsky B. The Ki67+ proliferation index correlates with increased cellular retinol-binding protein-1 and the coordinated loss of plakophilin-1 and desmoplakin during progression of cervical squamous lesions. Histopathology. 2007:51(1):87-97.

63. Young GD, Winokur TS, Cerfolio RJ, Van Tine BA, Chow LT, Okoh V, Garver RI Jr. Differential expression and biodistribution of cytokeratin 18 and desmoplakins in non-small cell lung carcinoma subtypes. Lung Cancer. 2002;36(2):133-41.

64. Boelens MC, van den Berg A, Vogelzang I, Wesseling J, Postma DS, Timens W, Groen HJ. Differential expression and distribution of epithelial adhesion molecules in non-small cell lung cancer and normal bronchus. J Clin Pathol. 2007;60(6):608-14.

65. Maynadier M, Chambon M, Basile I, Gleizes M, Nirde P, Gary-Bobo M, Garcia M. Estrogens promote cell-cell adhesion of normal and malignant mammary cells through increased desmosome formation. Mol Cell Endocrinol. 2012;364(1-2):126-33.

66. Dusek R, Attardi L. Desmosomes: new perpetrators in tumour suppression. Nat Rev Cancer. 2011;11(5):317.

67. Cipolat S, Hoste E, Natsuga K, Quist SR, Watt FM. Epidermal barrier defects link atopic dermatitis with altered skin cancer susceptibility. Elife. 2014;3:e01888

68. Natsuga K, Cipolat S, Watt FM. Increased bacterial load and expression of antimicrobial peptides in skin of barrier-deficient mice with reduced cancer susceptibility. J Invest Dermatol. 2016;136(1):99-106.

69. Nishimori T, Tomonaga T, Matsushita K, Oh-Ishi M, Kodera Y, Maeda T, Nomura F, Matsubara H, Shimada H, Ochiai T. Proteomic analysis of primary esophageal squamous cell carcinoma reveals downregulation of a cell adhesion protein, periplakin. Proteomics. 2006;6(3):1011-8.

70. Otsubo T, Hagiwara T, Tamura-Nakano M, Sezaki T, Miyake O, Hinohara C, Shimizu T, Yamada K, Dohi T, Kawamura YI. Aberrant DNA hypermethylation reduces the expression of the desmosome-related molecule periplakin in esophageal squamous cell carcinoma. Cancer Med. 2015;4(3):415-25.

71. Matsumoto K, Ikeda M, Sato Y, Kuruma H, Kamata Y, Nishimori T, Tomonaga T, Nomura F, Egawa S, Iwamura M. Loss of periplakin expression is associated with pathological stage and cancer-specific survival in patients with urothelial carcinoma of the urinary bladder. Biomed Res. 2014;35(3):201-6.

72. Matsumoto K, Ikeda M, Matsumoto T, Nagashio R, Nishimori T, Tomonaga T, Nomura F, Sato Y, Kitasato H, Iwamura M. Serum periplakin as a potential biomarker for urothelial carcinoma of the urinary bladder. Asian Pac J Cancer Prev APJCP. 2014;15(22):9927-31.

73. Li X, Zhang G, Wang Y, Elgehama A, Sun Y, Li L, Gu Y, Guo W, Xu Q. Loss of periplakin expression is associated with the tumorigenesis of colorectal carcinoma. Biomed Pharmacother. 2017;87:366-74.

74. Choi YK, Woo SM, Cho SG, Moon HE, Yun YJ, Kim JW, Noh DY, Jang BH, Shin YC, Kim JH, et al. Brain-metastatic triple-negative breast cancer cells regain growth ability by altering gene expression patterns. Cancer Genomics Proteomics. 2013;10(6):265-75.

75. Long HA, Boczonadi V, McInroy L, Goldberg M, Määttä A. Periplakindependent re-organisation of keratin cytoskeleton and loss of collective migration in keratin-8-downregulated epithelial sheets. J Cell Sci. 2006;119:5147-59.

76. Tonoike Y, Matsushita K, Tomonaga T, Katada K, Tanaka N, Shimada H, Nakatani Y, Okamoto Y, Nomura F. Adhesion molecule periplakin is involved in cellular movement and attachment in pharyngeal squamous cancer cells. BMC Cell Biol. 2011;12(1):41.

77. Yoshida T, Shiraki N, Baba H, Goto M, Fujiwara S, Kume K, Kume S. Expression patterns of epiplakin1 in pancreas, pancreatic cancer and regenerating pancreas. Genes Cells Devoted Mol Cellul Mech. 2008;13(7):667-78.

78. Blagoev B, Kratchmarova I, Ong SE, Nielsen M, Foster LJ, Mann M. A proteomics strategy to elucidate functional protein-protein interactions applied to EGF signaling. Nat Biotechnol. 2003;21(3):315-8.

79. Grapa CM, Mocan T, Gonciar D, Zdrehus C, Mosteanu O, Pop T, Mocan L. Epidermal growth factor receptor and its role in pancreatic cancer treatment mediated by nanoparticles. Int J Nanomed. 2019;14:9693-706.

80. Mclnroy L, Maatta A. Plectin regulates invasiveness of SW480 colon carcinoma cells and is targeted to podosome-like adhesions in an isoform-specific manner. Exp Cell Res. 2011;317(17):2468-78.

81. Sutoh Yoneyama M, Hatakeyama S, Habuchi T, Inoue T, Nakamura T, Funyu T, Wiche G, Ohyama C, Tsuboi S. Vimentin intermediate filament and plectin provide a scaffold for invadopodia, facilitating cancer cell invasion and extravasation for metastasis. Eur J Cell Biol. 2014;93(4):157-69.

82. Pawar H, Kashyap MK, Sahasrabuddhe NA, Renuse S, Harsha HC, Kumar P, Sharma J, Kandasamy K, Marimuthu A, Nair B, et al. Quantitative tissue proteomics of esophageal squamous cell carcinoma for novel biomarker discovery. Cancer Biol Ther. 2011;12(6):510-22.

83. Bausch D, Mino-Kenudson M, Fernandez-Del Castillo C, Warshaw AL, Kelly KA, Thayer SP. Plectin-1 is a biomarker of malignant pancreatic intraductal papillary mucinous neoplasms. J Gastrointest Surg. 2009;13(11):1948-54.

84. Bausch D, Thomas S, Mino-Kenudson M, Fernandez-del CC, Bauer TW, Williams M, Warshaw AL, Thayer SP, Kelly KA. Plectin-1 as a novel biomarker for pancreatic cancer. Clin Cancer Res. 2011;17(2):302-9.

85. Costa-Silva B, Aiello NM, Ocean AJ, Singh S, Zhang H, Thakur BK, Becker A, Hoshino A, Mark MT, Molina H, et al. Pancreatic cancer exosomes initiate pre-metastatic niche formation in the liver. Nat Cell Biol. 2015;17(6):816-26.

86. Shin SJ, Smith JA, Rezniczek GA, Pan S, Chen R, Brentnall TA, Wiche $\mathrm{G}$, Kelly KA. Unexpected gain of function for the scaffolding protein plectin due to mislocalization in pancreatic cancer. Proc Natl Acad Sci USA. 2013;110(48):19414-9.

87. Liu YH, Ho CC, Cheng CC, Pei RJ, Hsu YH, Yeh KT, Tsai MC, Lai YS. Pleomorphism of cancer cells with the expression of plectin and concept of filament bundles in human hepatocellular carcinoma. Res Commun Mol Pathol Pharmacol. 2007;120-121(1-6):43-54.

88. Liu YH, Cheng CC, Ho CC, Chao WT, Pei RJ, Hsu YH, Ho LC, Shiu BH, Lai YS. Plectin deficiency on cytoskeletal disorganization and transformation of human liver cells in vitro. Med Mol Morphol. 2011;44(1):21-6.

89. Niwa T, Saito H, Imajoh-ohmi S, Kaminishi M, Seto Y, Miki Y, Nakanishi A. BRCA2 interacts with the cytoskeletal linker protein plectin to form a complex controlling centrosome localization. Cancer Sci. 2009;100(11):2115-25.

90. Foisner R, Malecz N, Dressel N, Stadler C, Wiche G. M-phase-specific phosphorylation and structural rearrangement of the cytoplasmic cross-linking protein plectin involve p34cdc2 kinase. Mol Biol Cell. $1996 ; 7(2): 273-88$

91. Lheureux S, Gourley C, Vergote I, Oza AM. Epithelial ovarian cancer. Lancet. 2019;393(10177):1240-53.

92. Siegel RL, Miller KD, Jemal A. Cancer statistics, 2019. CA Cancer J Clin. 2019;69(1):7-34.

93. Lengyel E. Ovarian cancer development and metastasis. Am J Pathol. 2010;177(3):1053-64.

94. Motohara T, Katabuchi H. Ovarian cancer stemness: biological and clinical implications for metastasis and chemotherapy resistance. Cancers. 2019;11(7):907.

95. Nieman KM, Kenny HA, Penicka CV, Ladanyi A, Buell-Gutbrod R, Zillhardt MR, Romero IL, Carey MS, Mills GB, Hotamisligil GS, et al. Adipocytes promote ovarian cancer metastasis and provide energy for rapid tumor growth. Nat Med. 2011;17(11):1498-503.

96. Kipps E, Tan DSP, Kaye SB. Meeting the challenge of ascites in ovarian cancer: new avenues for therapy and research. Nat Rev Cancer. 2013;13:273-82. 
97. Meinhold-Heerlein I, Fotopoulou C, Harter P, Kurzeder C, Mustea A, Wimberger P, Hauptmann S, Sehouli J. The new WHO classification of ovarian, fallopian tube, and primary peritoneal cancer and its clinical implications. Arch Gynecol Obstet. 2016;293(4):695-700.

98. Tewari KS, Monk BJ. The 21st century handbook of clinical ovarian cancer. Cham: Springer; 2015.

99. Auersperg N, Maines-Bandiera SL. Culture and characterization of human ovarian surface epithelium. Methods Mol Med. 2001;39:169-74.

100. Murdoch WJ, Martinchick JF. Oxidative damage to DNA of ovarian surface epithelial cells affected by ovulation: carcinogenic implication and chemoprevention. Exp Biol Med. 2004;229(6):546-52.

101. Kurman RJ, Shih le M. The dualistic model of ovarian carcinogenesis: revisited, revised, and expanded. Am J Pathol. 2016;186(4):733-47.

102. Auersperg N, Wong AS, Choi KC, Kang SK, Leung PC. Ovarian surface epithelium: biology, endocrinology, and pathology. Endocr Rev. 2001;22(2):255-88.

103. Ahmed N, Maines-Bandiera S, Quinn MA, Unger WG, Dedhar S, Auersperg N. Molecular pathways regulating EGF-induced epitheliomesenchymal transition in human ovarian surface epithelium. Am J Physiol Cell Physiol. 2006;290(6):C1532-1542.

104. Permuth-Wey J, Sellers TA. Epidemiology of ovarian cancer. Methods Mol Biol. 2009;472:413-37.

105. Kurman RJ, Shih le M. Pathogenesis of ovarian cancer: lessons from morphology and molecular biology and their clinical implications. Int J Gynecol Pathol. 2008;27(2):151-60.

106. Levanon K, Crum C, Drapkin R. New insights into the pathogenesis of serous ovarian cancer and its clinical impact. J Clin Oncol. 2008;26(32):5284-93.

107. King MC, Marks JH, Mandell JB. Breast and ovarian cancer risks due to inherited mutations in BRCA1 and BRCA2. Science. 2003:302(5645):643-6.

108. Lakhani SR, Manek S, Penault-Llorca F, Flanagan A, Arnout L, Merrett S, McGuffog L, Steele D, Devilee P, Klijn JG, et al. Pathology of ovarian cancers in BRCA1 and BRCA2 carriers. Clin Cancer Res. 2004;10(7):2473-81.

109. Lee Y, Miron A, Drapkin R, Nucci MR, Medeiros F, Saleemuddin A, Garber J, Birch C, Mou H, Gordon RW, et al. A candidate precursor to serous carcinoma that originates in the distal fallopian tube. J Pathol. 2007:211(1):26-35.

110. Rogakou EP, Boon C, Redon C, Bonner WM. Megabase chromatin domains involved in DNA double-strand breaks in vivo. J Cell Biol. 1999;146(5):905-16

111. Karst AM, Levanon K, Drapkin R. Modeling high-grade serous ovarian carcinogenesis from the fallopian tube. Proc Natl Acad Sci USA. 2011;108(18):7547-52.

112. Medeiros F, Muto MG, Lee Y, Elvin JA, Callahan MJ, Feltmate C, Garber $J E$, Cramer DW, Crum CP. The tubal fimbria is a preferred site for early adenocarcinoma in women with familial ovarian cancer syndrome. Am J Surg Pathol. 2006;30(2):230-6.

113. Tan DS, Agarwal R, Kaye SB. Mechanisms of transcoelomic metastasis in ovarian cancer. Lancet Oncol. 2006;7(11):925-34.

114. Ahmed N, Stenvers KL. Getting to know ovarian cancer ascites: opportunities for targeted therapy-based translational research. Front Oncol. 2013;3:256.

115. Penet MF, Krishnamachary B, Wildes FB, Mironchik Y, Hung CF, Wu TC, Bhujwalla ZM. Ascites volumes and the ovarian cancer microenvironment. Front Oncol. 2018;8:595

116. Pakuła M, Uruski P, Niklas A, Woźniak A, Szpurek D, Tykarski A, MikułaPietrasik J, Książek K. A unique pattern of mesothelial-mesenchymal transition induced in the normal peritoneal mesothelium by highgrade serous ovarian cancer. Cancers. 2019;11(5):662.

117. Asem M, Young A, Oyama C, ClaureDeLaZerda A, Liu Y, Ravosa MJ, Gupta V, Jewell A, Khabele D, Stack MS. Ascites-induced compression alters the peritoneal microenvironment and promotes metastatic success in ovarian cancer. Sci Rep. 2020;10(1):11913.

118. Mikuła-Pietrasik J, Stryczyński Ł, Uruski P, Tykarski A, Książek K. Procancerogenic activity of senescent cells: a case of the peritoneal mesothelium. Ageing Res Rev. 2018;43:1-9.

119. Ranzinger J, Rustom A, Abel M, Leyh J, Kihm L, Witkowski M, Scheurich P, Zeier M, Schwenger V. Nanotube action between human mesothelial cells reveals novel aspects of inflammatory responses. PLoS ONE. 2011;6(12):e29537.
120. Caicedo A, Fritz V, Brondello JM, Ayala M, Dennemont I, Abdellaoui N, de Fraipont F, Moisan A, Prouteau CA, Boukhaddaoui H, et al. MitoCeption as a new tool to assess the effects of mesenchymal stem/stromal cell mitochondria on cancer cell metabolism and function. Sci Rep. 2015:5:9073.

121. Moschoi R, Imbert V, Nebout M, Chiche J, Mary D, Prebet T, Saland E, Castellano R, Pouyet L, Collette Y, et al. Protective mitochondrial transfer from bone marrow stromal cells to acute myeloid leukemic cells during chemotherapy. Blood. 2016;128(2):253-64.

122. Pasquier J, Guerrouahen BS, Al Thawadi H, Ghiabi P, Maleki M, AbuKaoud N, Jacob A, Mirshahi M, Galas L, Rafii S, et al. Preferential transfer of mitochondria from endothelial to cancer cells through tunneling nanotubes modulates chemoresistance. J Transl Med. 2013;11:94.

123. Sengodan SK, Sreelatha KH, Nadhan R, Srinivas P. Regulation of epithelial to mesenchymal transition by BRCA1 in breast cancer. Crit Rev Oncol Hematol. 2018;123:74-82.

124. Wang H, Bierie B, Li AG, Pathania S, Toomire K, Dimitrov SD, Liu B, Gelman R, Giobbie-Hurder A, Feunteun J, et al. BRCA1/FANCD2/BRG1driven DNA repair stabilizes the differentiation state of human mammary epithelial cells. Mol Cell. 2016:63(2):277-92.

125. Loret N, Denys H, Tummers P, Berx G. The role of epithelial-to-mesenchymal plasticity in ovarian cancer progression and therapy resistance. Cancers (Basel). 2019;11(6):838.

126. Takai M, Terai Y, Kawaguchi H, Ashihara K, Fujiwara S, Tanaka T, Tsunetoh S, Tanaka Y, Sasaki H, Kanemura M, et al. The EMT (epithelial-mesenchymal-transition)-related protein expression indicates the metastatic status and prognosis in patients with ovarian cancer. J Ovarian Res. 2014;7:76

127. Rafehi S, Ramos Valdes Y, Bertrand M, McGee J, Préfontaine M, Sugimoto A, DiMattia GE, Shepherd TG. TGF $\beta$ signaling regulates epithelial-mesenchymal plasticity in ovarian cancer ascites-derived spheroids. Endocr Relat Cancer. 2016;23(3):147-59.

128. Klymenko Y, Johnson J, Bos B, Lombard R, Campbell L, Loughran E, Stack MS. Heterogeneous cadherin expression and multicellular aggregate dynamics in ovarian cancer dissemination. Neoplasia. 2017;19(7):549-63.

129. Klymenko Y, Kim O, Loughran E, Yang J, Lombard R, Alber M, Stack MS. Cadherin composition and multicellular aggregate invasion in organotypic models of epithelial ovarian cancer intraperitoneal metastasis. Oncogene. 2017;36(42):5840-51.

130. Zhang L, Li Z, Gai F, Wang Y. MicroRNA-137 suppresses tumor growth in epithelial ovarian cancer in vitro and in vivo. Mol Med Rep. 2015;12(2):3107-14

131. Zhang P, Liu Y, Feng Y, Gao S. SNAIL gene inhibited by hypoxia-inducible factor 1a (HIF-1a) in epithelial ovarian cancer. Int J Immunopathol Pharmacol. 2016;29(3):364-75.

132. Pastushenko I, Brisebarre A, Sifrim A, Fioramonti M, Revenco T, Boumahdi S, Van Keymeulen A, Brown D, Moers V, Lemaire S, et al. Identification of the tumour transition states occurring during EMT. Nature. 2018;556(7702):463-8.

133. Knights A, Funnell A, Crossley M, Pearson R. Holding tight: cell junctions and cancer spread. Trends Cancer Res. 2012;8:61-9.

134. Hanahan D, Weinberg RA. Hallmarks of cancer: the next generation Cell. 2011;144(5):646-74.

135. Strauss R, Li ZY, Liu Y, Beyer I, Persson J, Sova P, Moller T, Pesonen S, Hemminki A, Hamerlik P, et al. Analysis of epithelial and mesenchymal markers in ovarian cancer reveals phenotypic heterogeneity and plasticity. PLOS ONE. 2011;6(1):e16186.

136. Qin S, Jiang J, Lu Y, Nice EC, Huang C, Zhang J, He W. Emerging role of tumor cell plasticity in modifying therapeutic response. Signal Transduct Target Ther. 2020;5(1):228.

137. Jolly MK, Boareto M, Huang B, Jia D, Lu M, Ben-Jacob E, Onuchic JN, Levine $\mathrm{H}$. Implications of the hybrid epithelial/mesenchymal phenotype in metastasis. Front Oncol. 2015;5:155.

138. Klymenko Y, Kim O, Stack MS. Complex determinants of epithelial: mesenchymal phenotypic plasticity in ovarian cancer. Cancers. 2017:9(8):104

139. Milliken D, Scotton C, Raju S, Balkwill F, Wilson J. Analysis of chemokines and chemokine receptor expression in ovarian cancer ascites. Clin Cancer Res. 2002;8(4):1108-14. 
140. Matte I, Lane D, Laplante C, Rancourt C, Piché A. Profiling of cytokines in human epithelial ovarian cancer ascites. Am J Cancer Res. 2012:2(5):566-80.

141. Moffitt L, Karimnia N, Stephens A, Bilandzic M. Therapeutic targeting of collective invasion in ovarian cancer. Int J Mol Sci. 2019;20(6):1466.

142. Bilandzic M, Rainczuk A, Green E, Fairweather N, Jobling TW, Plebanski M, Stephens AN. Keratin-14 (KRT14) positive leader cells mediate mesothelial clearance and invasion by ovarian cancer cells. Cancers. 2019;11(9):1228

143. Romero I, Bast RC Jr. Minireview: human ovarian cancer: biology, current management, and paths to personalizing therapy. Endocrinology. 2012;153(4):1593-602.

144. Patel S, Kumar L, Singh N. Metformin and epithelial ovarian cancer therapeutics. Cell Oncol (Dordr). 2015;38(5):365-75.

145. Bapat SA, Mali AM, Koppikar CB, Kurrey NK. Stem and progenitor-like cells contribute to the aggressive behavior of human epithelial ovarian cancer. Cancer Res. 2005;65(8):3025-9.

146. Zhang S, Balch C, Chan MW, Lai HC, Matei D, Schilder JM. Identification and characterization of ovarian cancer-initiating cells from primary human tumors. Cancer Res. 2008:68:4311-20.

147. Ahmed N, Abubaker K, Findlay JK. Ovarian cancer stem cells: Molecular concepts and relevance as therapeutic targets. Mol Aspects Med. 2014;39:110-25.

148. Abdullah LN, Chow EK. Mechanisms of chemoresistance in cancer stem cells. Clin Transl Med. 2013;2(1):3.

149. Al-Alem LF, Pandya UM, Baker AT, Bellio C, Zarrella BD, Clark J, DiGloria CM, Rueda BR. Ovarian cancer stem cells: what progress have we made? Int J Biochem Cell Biol. 2019;107:92-103.

150. Abubaker K, Latifi A, Luwor R, Nazaretian S, Zhu H, Quinn MA, Thompson EW, Findlay JK, Ahmed N. Short-term single treatment of chemotherapy results in the enrichment of ovarian cancer stem cell-like cells leading to an increased tumor burden. Mol Cancer. 2013;12:24.

151. Ahmed N, Abubaker K, Findlay J, Quinn M. Cancerous ovarian stem cells: obscure targets for therapy but relevant to chemoresistance. J Cell Biochem. 2013;114(1):21-34.

152. Samardzija C, Greening DW, Escalona R, Chen M, Bilandzic M, Luwor R Kannourakis G, Findlay JK, Ahmed N. Knockdown of stem cell regulator Oct4A in ovarian cancer reveals cellular reprogramming associated with key regulators of cytoskeleton-extracellular matrix remodelling. Sci Rep. 2017:7:46312.

153. Garson K, Vanderhyden BC. Epithelial ovarian cancer stem cells: underlying complexity of a simple paradigm. Reproduction. 2015;149(2):R59-70.

154. van Neerven SM, Tieken M, Vermeulen L, Bijlsma MF. Bidirectional interconversion of stem and non-stem cancer cell populations: a reassessment of theoretical models for tumor heterogeneity. Mol Cell Oncol. 2016:3(2):e1098791.

155. Abubaker K, Luwor RB, Zhu H, McNally O, Quinn MA, Burns CJ, Thompson EW, Findlay JK, Ahmed N. Inhibition of the JAK2/STAT3 pathway in ovarian cancer results in the loss of cancer stem cell-like characteristics and a reduced tumor burden. BMC Cancer. 2014;14:317.

156. Forte E, Chimenti I, Rosa P, Angelini F, Pagano F, Calogero A, Giacomello A. Messina E. EMT/MET at the crossroad of stemness, regeneration and oncogenesis: the Ying-Yang equilibrium recapitulated in cell spheroids. Cancers. 2017:9(8):98.

157. Karam A, Santiskulvong C, Fekete M, Zabih S, Eng C, Dorigo O. Cisplatin and PI3kinase inhibition decrease invasion and migration of human ovarian carcinoma cells and regulate matrix-metalloproteinase expression. Cytoskelton. 2010;67:535-44.

158. Bilandzic M, Chu S, Wang Y, Tan HL, Fuller PJ, Findlay JK, Stenvers KL. Betaglycan alters NFkappaB-TGFbeta2 cross talk to reduce survival of human granulosa tumor cells. Mol Endocrinol. 2013:27(3):466-79.

159. Arend RC, Londono-Joshi Al, Straughn JM Jr, Buchsbaum DJ. The Wnt/ beta-catenin pathway in ovarian cancer: a review. Gynecol Oncol. 2013;131(3):772-9.

160. Choi YP, Shim HS, Gao MQ, Kang S, Cho NH. Molecular portraits of intratumoral heterogeneity in human ovarian cancer. Cancer Lett. 2011;307(1):62-71.

161. Li H, Li J, Feng L. Hedgehog signaling pathway as a therapeutic target for ovarian cancer. Cancer Epidemiol. 2016:40:152-7.
162. Aparicio T, Baer R, Gautier J. DNA double-strand break repair pathway choice and cancer. DNA Repair (Amst). 2014;19:169-75.

163. Lord CJ, Ashworth A. PARP inhibitors: synthetic lethality in the clinic. Science. 2017;355(6330):1152-8.

164. Bi Y, Verginadis II, Dey S, Lin L, Guo L, Zheng Y, Koumenis C. Radiosensitization by the PARP inhibitor olaparib in BRCA1-proficient and deficient high-grade serous ovarian carcinomas. Gynecol Oncol. 2018;150(3):534-44

165. Dasa SSK, Diakova G, Suzuki R, Mills AM, Gutknecht MF, Klibanov AL, Slack-Davis JK, Kelly KA. Plectin-targeted liposomes enhance the therapeutic efficacy of a PARP inhibitor in the treatment of ovarian cancer. Theranostics. 2018:8(10):2782-98.

166. Pettitt SJ, Krastev DB, Brandsma I, Drean A, Song F, Aleksandrov R, Harrell Ml, Menon M, Brough R, Campbell J, et al. Genome-wide and highdensity CRISPR-Cas9 screens identify point mutations in PARP1 causing PARP inhibitor resistance. Nat Commun. 2018;9(1):1849.

167. Bellio C, DiGloria C, Foster R, James K, Konstantinopoulos PA, Growdon WB, Rueda BR. PARP inhibition induces enrichment of DNA repair-proficient CD133 and CD117 positive ovarian cancer stem cells. Mol Cancer Res MCR. 2019:17(2):431-45.

168. Augustine T, Maitra R, Zhang J, Nayak J, Goel S. Sensitization of colorectal cancer to irinotecan therapy by PARP inhibitor rucaparib. Invest New Drugs. 2019;37(5):948-60.

169. Alkema NG, Wisman GB, van der Zee AG, van Vugt MA, de Jong $S$. Studying platinum sensitivity and resistance in high-grade serous ovarian cancer: different models for different questions. Drug Resist Updat. 2016;24:55-69.

170. Taylor KN, Eskander RN. PARP inhibitors in epithelial ovarian cancer. Recent Pat Anticancer Drug Discov. 2018;13(2):145-58.

171. Walsh C. Targeted therapy for ovarian cancer: the rapidly evolving landscape of PARP inhibitor use. Minerva Ginecol. 2018:70(2):150-70

172. Ahmed N, Greening D, Samardzija C, Escalona RM, Chen M, Findlay JK, Kannourakis $\mathrm{G}$. Unique proteome signature of post-chemotherapy ovarian cancer ascites-derived tumor cells. Sci Rep. 2016;6:30061.

173. Latifi A, Luwor RB, Bilandzic M, Nazaretian S, Stenvers K, Pyman J, Zhu $H$, Thompson EW, Quinn MA, Findlay JK, et al. Isolation and characterization of tumor cells from the ascites of ovarian cancer patients: molecular phenotype of chemoresistant ovarian tumors. PLOS ONE. 2012; $7(10): e 46858$.

174. Shield K, Riley C, Quinn MA, Rice GE, Ackland ML, Ahmed N. Alpha2beta1 integrin affects metastatic potential of ovarian carcinoma spheroids by supporting disaggregation and proteolysis. J Carcinog. 2007:6:11.

175. Ahmed N, Escalona R, Leung D, Chan E, Kannourakis G. Tumour microenvironment and metabolic plasticity in cancer and cancer stem cells: perspectives on metabolic and immune regulatory signatures in chemoresistant ovarian cancer stem cells. Semin Cancer Biol. 2018;53:265-81.

176. Auer K, Bachmayr-Heyda A, Sukhbaatar N, Aust S, Schmetterer KG, Meier SM, Gerner C, Grimm C, Horvat R, Pils D. Role of the immune system in the peritoneal tumor spread of high grade serous ovarian cancer. Oncotarget. 2016;7(38):61336-54.

177. Chan E, Luwor R, Burns C, Kannourakis G, Findlay JK, Ahmed N. Momelotinib decreased cancer stem cell associated tumor burden and prolonged disease-free remission period in a mouse model of human ovarian cancer. Oncotarget. 2018:9(24):16599-618.

178. Zeineddine D, Hammoud AA, Mortada M, Boeuf H. The Oct4 protein: more than a magic stemness marker. Am J Stem Cells. 2014;3(2):74-82.

179. Samardzija C, Luwor R, Volchek M, Quinn M, Findlay J, Ahmed N. A critical role of Oct $4 \mathrm{~A}$ in mediating metastasis and disease-free survival in a mouse model of ovarian cancer. Mol Cancer. 2015:14(1):1-19.

180. Castanon MJ, Walko G, Winter L, Wiche G. Plectin-intermediate filament partnership in skin, skeletal muscle, and peripheral nerve. Histochem Cell Biol. 2013;140(1):33-53.

\section{Publisher's Note}

Springer Nature remains neutral with regard to jurisdictional claims in published maps and institutional affiliations. 